\title{
WHERE TO NOW? THE
}

\section{POTENTIAL FOR \\ CLIMATE CHANGE- \\ RELATED MIGRATION}

What is the state of the international approach to the potential problem of climate change-related migration, and what contribution does Hodgkinson, Anderson, Burton and Young's proposed Climate Change Displaced Persons Convention make to the international approach? 
A Thesis Submitted to the Victoria University of Wellington in Partial Fulfillment of the Requirements for the Degree of Master of International Relations (MIR)

School of History, Philosophy, Political Science and International Relations

Victoria University of Wellington

Anne Cawthorn

300071159

June 2012 


\section{ACKNOWLEDGEMENTS}

This thesis would not have been possible without the help and support of

Martin, Frances, Bella, and Alex; of Kate McMillan and my colleagues Paul,

Charlotte, Steph and Jo. 


\section{LIST OF ACRONYMS}

General Acronyms

AOSIS Alliance of Small Island States (Negotiating group under the UN)

CCCDP Convention for Climate Change Displaced Persons (Hodgkinson, Burton, Anderson and Young)

IPCC Intergovernmental Panel on Climate Change (UNFCCC's scientific arm, which brings together scientists and science on climate change from all over the world)

SIDS Small Island Developing States

SIS Small Island States

UNFCCC United Nations Framework Convention on Climate Change (Convention establishing responses to anthropogenic climate change. Successor document currently under negotiation by 195 states.)

UDHR Universal Declaration of Human Rights

Convention for Climate Change Displaced Persons Acronyms

CCDO Climate Change Displacement Organisation (central body of the Convention, comprised of four separate bodies)

- Assembly Council

- Climate Change Displacement Fund

- Climate Change Displacement Environment and Science Organisation

- Climate Change Displacement Implementation Groups

CCDF Climate Change Displacement Fund

CCDESO Climate Change Displacement Environment and Science Organisation

CCDIGs Climate Change Displacement Implementation Groups 


\section{Introduction}

Climate change may be a relatively new phenomenon, but its effects are being felt throughout the world and having a significant impact on peoples' lives in many countries. Some of those most keenly feeling the effects live in areas that are particularly vulnerable to destabilizing factors acting in conjunction with existing challenges. The effects of climate change are an exacerbating factor in sometimes already difficult lives.

In some areas, the effects of climate change are or may become such that the inhabitants contemplate migration to find a more viable life elsewhere, either in their own country or in another country. It is by no means guaranteed that the effects of climate change will inexorably lead people, such as those in low-lying small island states, to migrate outside their country, particularly if there are adequate measures taken to mitigate and adapt to the effects of climate change.

However, it is becoming increasingly clear that the potential for climate changerelated migration is drawing near, if it has not already arrived, as a factor for some people's decisions to migrate internally or externally. Some work currently underway considers approaches to dealing with climate change-related migration and the possible related issues around human rights protections and practical management. Climate change is an amorphous, complex and politically challenging issue for governments and stakeholders to deal with. Its effects on peoples' lives can be significant, especially in conjunction with existing development, environmental, and economic challenges. It is important to ensure that any approach created is necessary, in light of existing mechanisms and available 
resources, and that it does not disadvantage any other groups of people through its creation or functioning.

This thesis considers the state of the international approach to the potential problem of climate change-related migration. One recently developed approach was a proposed Climate Change Displaced Persons Convention, which has been formulated by Hodgkinson, Burton, Anderson and Young (2010).

A range of information was considered to try and find a balance between the attempt to deal with climate change as a public and foreign policy issue and the human reactions and subsequent choices people make in dealing with the effects of climate change. Due to the complications of holding a position as a public servant working in the field of responses to climate change, I decided to use a methodology that would enable me to remain a step removed from the process, to avoid influencing responses.

The thesis reviews current literature and experiences on climate change and migration, particularly in the Pacific, identifies key issues, and assesses the potential effectiveness of the Convention in addressing the issues identified. Information sources included drawing on reports of first hand experience of climate change related migration and those living in the front line on the islands, experiences of working in the public and NGO sectors, and academic considerations of how to address climate change and migration.

This area of climate change and potential migration which is developing and nebulous, and the potential value of the Convention is broader than one area picked up by traditional lenses. Traditional political science or international relations political structures were not used to frame the thesis as no one lens could helpfully set a broad enough base for consideration. For example, using governance theory would have started from the presumption that there is a tangible, discernible and existing process underway which needs only a structure to govern it. As this thesis argues, migration resulting from climate change is not inevitable, therefore to use 
governance theory would ignore considerations of approaches including actions that would render migration unnecessary, which is the logical and identified best outcome for those facing severe impacts of climate change. Traditional approaches are not considered suitable for this analysis.

The first section of the thesis, Section A, explains the scientific relationship between the process of climate change and human activity. Recognising the link between climate and a sustainable, viable life in particularly affected areas, the potential direct link between climate change and a need for human migration is identified. Having established the link the thesis discusses the normative weight and relative value of referential terms used in the context of potential migration and identifies an optimal definition for the potential problem: climate change related migration.

Section B critically examines existing migration theory and current understandings of and approaches to migration, acknowledging that migration is complex and part of patterns of human behavior responding to environmental and other factors influencing a sustainable life. It acknowledges that climate change related migration potentially occurs under situations for which traditional migration theory does not account for. Recognising the danger of assuming that migration is the only possible response to the impacts of climate change, the spectrum of responses to climate change is identified, placing migration within the spectrum rather than as the inevitable end point or sole option for dealing with the effects of climate change.

The third section, Section C, identifies gaps in existing initiatives and approaches to addressing climate change related migration. The gaps are: assumption of a human rights basis or facet to the potential problem; placing potential climate change related migration in consciousness as a preventable and early intervention issue; the complexity and sensitivity of migration as a human and political process in and of itself; competition between climate change related migration and other pressing social or international crises; and the difficulty of raising a policy response or even attempt to create a policy response in short term domestic political timeframes. 
The final section specifically examines the Convention for its treatment of the assumptions identified in previous sections. The Convention proposed by Hodgkinson, Anderson, Burton and Young is described and discussed, explaining its structure and technical approach. The proposed Convention is assessed as a possible contribution to filling the identified gaps and addressing some of the inherent challenges associated with addressing potential climate change related migration. Drawing on the assumptions identified in previous sections and the effects those assumptions have on understandings of and development of approaches to dealing with climate change related migration, the final section examines how usefully the proposed Convention deals with assumptions in creating potential climate change related migration. Finally, the thesis examines the Convention's effectiveness at taking an objective and principled approach to the issue of climate change related migration with a view to contributing to international policy. 


\section{Section A}

\section{Climate change and its potential implications for migration}

This section describes that climate change has a number of impacts on the environment, which could degrade the environment to the point where people cannot maintain a sustainable life. It is very difficult to define what a climate change related migrant would look like and to differentiate migration caused by the effects of climate change from other types of migration. The problem under consideration is that the direct or indirect effects of climate change may impact people's lives to the extent that they are forced to consider moving within or outside their country to achieve a sustainable life. The importance of identifying human causes and factors in climate change lies in considering approaches to addressing its effects. It is crucial that a definition of the problem accurately reflects the complex decision making process for those affected and considering whether to migrate. Therefore the definition 'climate change-related migration' is used to avoid, as far as possible, creating misconceptions about the relationship between influencing factors and the decision to move.

\section{Climate change, its effects, and people movement}

The Intergovernmental Panel on Climate Change (IPCC) in its most recent Working Group Report states that "...warming of the climate system is unequivocal, as is now evident from observations of increases in global average air and ocean temperatures, widespread melting of snow and ice, and rising global average sea level" (Canziani et al, 2007, p.5). Climate change as a concept continues to draw much discussion about its veracity and origins, despite the fact that (as Burson points 
out) "...scientific consensus is crystallising around a realisation that climate change, more specifically, anthropogenic climate change, is real and constitutes a near-term threat" (Burson, 2010, p.9). The complexity of the issue and the detail of scientific evidence and modelling make climate change a challenging field to work with in a public and foreign policy sense. Understanding the scientific basis is important for understanding the links between everyday activities, climate change and human movement.

Climate is different from daily weather, which we all have a personal grasp of, in that 'climate' constitutes the distribution of weather patterns over a long period of time, decades or more. In this sense, climate can be understood as long-term average weather. The earth's climate has always been subject to natural cycles, oscillating between ice ages and warm periods (such as the temperate climate we are currently experiencing). In the decades since the Industrial Revolution, scientists have discovered a number of changes in observed phenomena which are cause for concern. These are warming oceans, significant ice loss from glaciers and polar ice caps, increased atmospheric concentrations of greenhouse gases, particularly carbon dioxide (CO2), and a change in the directional warming pattern across hemispheres (Canziani et al, 2007; Morgan, 2009; Reisinger, 2009).

All of these things can and do happen naturally, as part of the usual flux within and between warming and cooling cycles. However, the changes and the speed of change observed since the beginning of the twentieth century have been atypical of normal patterns. They have reached beyond even the predictions of scientific models and in some cases historic record, even when the widest plausible range of expected natural variation is taken into account. Oceans are warming at both surface level (where changes of weather and short-term climate effects, such as La Niña, are often reflected) and deep ocean level, where the earth's long-term heat energy is stored. Ice loss is occurring at unusual levels and acceleration, and the pattern of global warming (comprised of land, sea and air temperature increases) has reversed so the Northern hemisphere is warming before the Southern (Canziani et al, 2007; Morgan, 2009; Reisinger, 2009). 
Fossil fuel combustion accounts for more than $75 \%$ of the increase in atmospheric carbon dioxide, with most of the remainder of the increase in greenhouse gases coming from changes to land-use such as deforestation and altered agricultural processes (Canziani et al, 2007). Fossil fuel burning and changing agricultural practices (e.g. from forest to pasture) release carbon dioxide into the atmosphere, thereby altering the balance of carbons (Canziani et al, 2007; Morgan, 2009; Reisinger, 2009). "It's like adding clear water to a bathful of dyed water, and even though some proportion of the dyed water is disappearing down the plughole (into natural sinks such as the oceans and biota), the rate of ingress is exceeding the rate of outflow. The bath level is rising, and the hue of the dye is getting paler". (Morgan, 2009, p. 157) Carbon dioxide concentrations in the earth's atmosphere act like a thermal blanket, trapping heat in a 'greenhouse effect' and, to put it simply, making the world hotter.

Taking all these indicators of warming and change together, and looking at the net warming effect of increased and long-term carbon dioxide concentrations in the atmosphere, scientists agree that the pattern is beyond any natural projection, and very likely to have been caused by human activity, in particular fossil fuel burning and changing agricultural practices. "Human greenhouse gas emissions have an overall influence on impacts around the world, because there is no other way to explain the global-scale agreement between greenhouse gas concentrations, the pattern of global temperature increases, and the documented effects that have followed increasing temperatures on every continent and in most oceans". (Reisinger, 2009, p. 60) The importance of identifying human causes and factors in climate change lies in considering approaches to addressing its effects, as will be discussed later in this paper.

The effects of anthropogenic climate change can affect the environment in ways that, depending on responses to or preparation for those effects, could precipitate the uninhabitability of some areas and potentially migration away from affected areas. The effects of a warming climate, in conjunction with the changes to currents 
and weather patterns (e.g. precipitation, cloudiness, extreme events), cause sea level rise. Climate change is also having a gradual effect on changing weather patterns which directly affect lives and livelihoods, in particular those of communities reliant on subsistence agriculture, fishing, and habitation close to the sea, deltas, or in water-deprived areas like deserts. Changes to weather can also cause flooding, and possibly influence extreme weather events (Canziani et al, 2007; Morgan, 2009; Reisinger, 2009; Barnett, 2003). There is a wide range of other effects of climate change, including flooding, wildfires, drought, extremes of hot and cold temperatures, and ocean acidification, caused by increased atmospheric concentrations of carbon dioxide.

Climate change is not the only factor that changes environments and affects human activity. Natural factors that change weather and land include tectonic movement, patterns of land movement such as longshore drift and erosion, and the movement of land and water from flooding and wind (Canziani et al, 2007; Morgan, 2009; Reisinger, 2009). Small island states (SIS) such as Kiribati and Tuvalu in the Pacific are particularly vulnerable to such effects of climate change, because of their small size, relative isolation, and limited human resource capacity to counter the changes taking place. Hodgkinson et al identify small island states as likely to be first and worst affected by the effects of climate change in their proposed Convention for Climate Change Displaced Persons (CCCDP), and part of their proposal specifically addresses the inhabitants of small island states (Hodgkinson, Burton, Anderson, and Young, 2010).

Climate change and natural processes all affect ecosystems and land in ways that may make it difficult, undesirable or, at worst, impossible for people to continue a realistic and meaningful life on affected land. Some effects are likely to be particularly important for SIS. Warm oceans can lead to coral bleaching, which in turn provides less food and a degraded habitat for fish and other sea life that provide the sustenance and livelihood for people living on a nearby shoreline. That shoreline may be subject to a compounding effect of climate-change-induced sea level rise and tectonic movement (which could theoretically cancel each other out, 
depending on the direction of tectonic movement), resulting in less shoreline and diminished buffer for more frequent and intense extreme weather events such as cyclones.

Sea level rise can increase the salinity of fresh water lenses in islands and atolls, by increasing the pressure that sea water puts on the earth around the lens, which in turn causes leaching through the soil. A pressure change can also alter the level of the water table, lowering the amount and physical level (distance from the ground) of fresh water relative to salt water. These water-related effects of climate change are likely to have particularly profound impacts on small island states in the Pacific, and could be a factor driving migration. However, changes to sea level or availability of fresh water are not necessarily climate-change-related.

Following a period of almost no change in sea level rise between $0 A D$ and 1900, the IPCC warned in its 2007 report of "strong evidence of global sea level rising" at an increasing rate. Sea level is projected to rise at an even greater rate in the next century (Canziani et al, 2007). Sea level rise has three causes - first is thermal expansion, where warm water particles take up more space than cool water particles, and this phenomenon is expected to account for about half the total rise for the twentieth century. The second cause is tectonic change - both the natural movement of the earth's plates which can lower or raise land (the latter seen in the changes to the height above sea level of the Cartaret Islands), and the tectonic recovery of the earth's crust through expansion as the large ice caps melt, or when "liberated from the burden of ice masses", as Morgan poetically put it. (Morgan, 2009, p. 130) Third, the melting of ice releases fresh water into the oceans, increasing total volume. (Canziani et al, 2007; Morgan, 2009; Barnett, 2003).

The projections for sea level rise this century vary widely. The IPCC's estimates (widely used by academics and scientists) are based on a number of potential scenarios and range from 0.18 to 0.59 metres. Others have taken a more extreme possible range, and come up with 1-2 metres (Allison et al, in Carius and Maas, n.d.). 
The uncertainty in these figures rests on the behaviour of the other causal factors, particularly the response of ice sheets to the warming climate (Reisinger, 2009). Sea level rise is not necessarily linear and uniform across a region, and depends on the sum of various factors. In relation to the Pacific, other factors include 'growing' coral islands due to normal coral development and tectonic processes, and regional variations (Nicholls, 2003). Some Pacific Island countries are particularly vulnerable because of their low elevation (Tuvalu being only 4.6 metres above sea level at its highest point), their high ratio of coastline, and relative isolation. Adaptation to sea level rise is vital and unavoidable, given the IPCC predictions and current trends. The extent and cost of the effects of sea level rise depend on various factors, including the pace and mix of adaptation activities (Nicholls, 2003).

However, it now seems likely that the rise will be greater than the IPCC's original predictions, and beyond the $21^{\text {st }}$ century there will probably be substantial additional sea level rise. Mitigation efforts have the slowest effect on sea level rise, in comparison to other climate change effects (Nicholls, 2003).

All of the natural changes discussed above pose challenges for countries particularly vulnerable to the effects of climate change, and those in the Pacific face a situation compounded by the natural features of their lands and ecosystems, and the human activity of their inhabitants. For the Pacific Islands, a natural factor that can increase vulnerability to climate change effects includes a high proportion of low-lying coastal land, which is often subject to severe erosion during seasonal storms and natural processes. Many Pacific Island countries comprise clusters of small islands isolated from large landmasses. Atoll countries such as Kiribati are particularly vulnerable, which has 32 very low-lying atolls (and one island), spread over an area of ocean the size of India, and far from other countries. Such countries are reliant on small fresh water lenses, and are at the mercy of rainfall for their replenishment. (Storey, and Hunter, (2010).

\section{Climate change-related migration}


As discussed, climate change's environmental effects are potentially negative for humans as they combine with other hardship factors and force people to move in order to maintain acceptable lives. In examining the state of the international approach to the potential problem of people who have had to move to deal with the effects of climate change, and the potential contribution made by Hodgkinson, Burton, Anderson and Young's proposal, it is important to be identify who these people moving are. People who may move as a result of the effects of climate change are not necessarily considered as part of existing migration definitions, and the circumstances around that movement may be different from other types of migration. Singling out climate change-related migration suggests that it is a special case, which needs a special definition. As Barnett says, it is less the movement than the political and institutional responses to that movement which are important and a definition is a step on the way to determining those responses (Barnett, 2003). Without a definition, is there really a specific problem that needs attention?

Dun and Gemenne provide the most succinct answer "...[definitions] determine entitlement to rights and establish the threshold for accessing any protection regime" (Dun and Gemenne, 2008). The international community has discovered a gap in managing climate change-related movement of people, and is seeking starting points for dealing with it. Hodgkinson, Burton, Anderson and Young's proposed Convention is one possible springboard, but there is not yet international consensus on what the problem of climate-change-related migration encompasses or how to identify its subjects.

When attempting to develop a definition to cover climate change-related movement, it is necessary to be very careful about causality and the edges of the problem (as noted above). Many factors can be involved in a decision to migrate, and while they can coalesce around a person's environment, climate change may be only one factor of the combined causes of lifestyle degradation. Thus it is important to be selective about terminology - whether "environmental" or "climate change" should be the prefix to "migration". This may seem to be splitting hairs, but the prefix would be important in the event that, for example, an insurance company or 
international organisation required a degree of certainty as to the cause of movement (and associated loss) for which they are providing compensation and assistance. As above, attributing the reason for migration solely to climate change is nigh impossible, as is proving that climate change was the predominant or sole cause of a particular environmental degradation.

The use of the prefix "environmental" could include factors such as the negative impacts of public works projects such as dams, or problems from over-intensive farming of unsuitable land (Myers, 2001). Within the possible definition itself are two terms with complex meanings. "Climate change" is a difficult term in and of itself, when really what is meant in contexts such as this, is 'the effects of climate change on the environment that were negative from the perspective of human life as we know it'. The IPCC has been clear that climate change is a hugely complex scientific phenomenon, and it is not always possible, if ever, to determine what specific events or effects on a local scale are 'climate change' and what comprise weather and normal environmental processes and fluctuations. The definition's second component also causes difficulties in a clear definition including the subjects - the 'migrants' or 'refugees'.

Media reporting often uses the term 'climate change refugees', which conveys a sense of compulsion, and urgency, of people fleeing (Mortreux, and Barnett, 2009, 105). The rights of refugees are protected under international law. The Refugee Convention provides a system for protecting the rights of people rendered stateless because of political or religious persecution, including when the state has been the persecutor. However, people who move (temporarily, permanently, internally or externally) in relation to the effects of climate change are not stateless and therefore they still have an entity (the state) that is responsible for protecting their rights (Burson, 2010; Barnett, 2003). Therefore, 'refugee' is not necessarily appropriate in this context.

A suitable definition around climate change-related movement of people would help direct identification of those likely to be affected, and focus a response. Finding a 
useful and appropriate definition for climate change-related movement of people is a source of much discussion among academics and others involved in the field. Consensus is forming that using the term 'refugee' is not helpful (as indicated above), and its use is to be avoided, to prevent undermining its normative weight for those classified as refugees under the Refugee Convention (Black, 2001; Barnett, 2003). Furthermore, "Climate change refugee" and "environmental refugee" are terms with no legal basis under international law regardless of how widely they are used. People in the Pacific and other climate change-related migrants have also expressed opposition to the use of the term as it suggests that they have no choice in their movement, and that their rights are covered by an international system neither of which is the case (Macey, 2009; Barnett, 2001).

Yet in order to be able to usefully discuss ways to deal with the issues that arise when people have to move for reasons that may include the negative effects of climate change on their environment, some sort of definition needs to be found. While it may make the most sense in terms of specifically codifying motivations for movement, "environmental migration" is somewhat broader than what is needed to accurately address the issue of climate change-related migration, which has a strong focus on the effects of climate change.

Most often used now (and to better effect) are the phrases "climate-induced migration" and "climate migrants", with "environmental migrants" in the vanguard for situations more related to environmental issues than climate change such as flooding, volcanoes, etc (International Organisation for Migration, 2004). The Asian Development Bank uses "climate-induced migration" and "climate migrant" to "...refer to the persons or groups who, for compelling reasons of climate-induced changes in the environment that adversely affect their lives or living conditions, are obliged to move from their habitual homes, or choose to do so, within their country of residence or abroad" (Asian Development Bank, 2011, 5). These definitions give the best sense of the nexus between climate change and the movement of people, and the best basis for thinking about how to formulate an approach to dealing with 
the possible effects of climate change migration in the Pacific region and further afield.

For the purposes of this thesis, and acknowledging the complexity of decisions to migrate (as discussed in Section B), the definition used will be "climate changerelated migration". This is selected to incorporate the idea that climate change is not the only factor that caused migration from a particular area, and to assume so (as suggested in 'climate-induced migration') is over-simplifying and unhelpful.

\section{The potential problem}

The effects of climate change on natural and human environments, possibly in conjunction with a range of other factors, may affect peoples' lives to an extent that the inhabitants of a particularly affected area need to move away to continue a meaningful, productive and less threatened life. Depending on their specific situation, they could move a short distance to where the threats and effects are lesser, or further afield to a more distant part of their country, or in some cases they could move to another country entirely. These movements are likely to be of a type and manner that is not currently provided for under existing human rights and people-movement instruments.

There is a great deal of uncertainty as to the extent of the possible problem of climate change-related migration, in terms of how many people will be affected. In part this uncertainty relates to the scientific prediction around the physical effects of climate change, as it is difficult, if not impossible, to accurately predict when the effects of climate change will reach a point at which people need to move from an area. The uncertainty also relates to the wide range of human and environmental resilience to the effects of climate change, and the complexity of people's decisionmaking around migration.

As will be shown in Section B, the connection between the effects of climate change on the environment and peoples' decisions around movement is not linear or simple. Humans have always and will continue to move for a variety of reasons and to a 
variety of locations, and there is a system of legal frameworks that has built up over time to manage the movement of people and protect them during their moves.

The system was constructed on the basis of movement that stems from different motivations, and is generally of a different type, than that induced by environmental problems such as the effects of climate change. This design and functionality in itself is not the system's detriment, but it is argued that the framework is inappropriate for dealing with climate change-related migration.

In the absence of a suitable framework, small island states, such as those in the Pacific, are particularly vulnerable to the potential for climate change-related migration on two fronts: the geographical-geological, and the socio-political. Those states that are most likely to develop climate change-related migrants have neither the physical nor human resources to deal internally with climate change-related migration, nor the political weight to effect a formal global approach to the problem. 


\section{Section B}

\section{Current approaches to the potential problem of climate change-related migration}

This section examines the existing migration theory and approaches to dealing with potential triggers for migration, arguing that the effects of climate change intersect with human activity with migration as one possible option for dealing with the impact of climate change. Migration is not a new, unique or simple process, and non-environmental human factors play a significant part in the causes of migration. The thesis argues that narrowing our focus to climate change related factors overlooks and risks over-simplifying the process of migration. The thesis argues that migration theory provides a useful background but there are difficulties using it to address potential climate change related migration because of a lack of clarity around numbers of those potential migrants, possible actions to mitigate the effects of climate change, and individuals' complex decision making processes.

Portrayal of the effects of climate change in the context of possible migration can also be unhelpfully over-simplified. For example, in the Pacific the complex interrelationship between isolation, scarce resources, lack of infrastructure and urbanization trends are often overlooked and can be rolled up together and attributed to climate change. It is argued that this changes the appreciation of and approaches to dealing with the effects of climate change, which could be addressed and mitigated through a spectrum of adaptation and mitigation activities. There is a 
range of regional and international approaches within which the potential for climate change related migration can be addressed, but it is argued that by and large these operate independently and without sufficient consideration of the complexity of migration decisions.

Current approaches to the potential problem of climate change-related migration cover various angles of the issue but remain fledgling and disparate. Generally, they deal with one aspect of possible option, such as migration, and do not approach the issue as a whole (for example taking into account the adaptation - migration spectrum). Approaches remain relatively unformed due to the difficulty of identifying likely numbers, whether states will mitigate to an extent that has a significant positive impact on the effects of climate change as they relate to potential migration, and difficulty of planning for such an amorphous potential issue with all its complexities of decision-making and political uncertainty.

The complexity of framing current work on the issue of climate change-related migration is illustrated by a much-publicised case from the Pacific a case that, despite its presentation is not climate change-related migration. The case of the Cartaret Islanders is often held up as one of the first instances of climate changerelated migration. 2,600 islanders relocated from the Cartaret Islands to Bougainville in Papua New Guinea, subsequently relocated to another island and then, after some time, decided to move back to their original habitations despite the degradation to the environment. However, the less told side of the story is that the degradation to their environment was not in fact caused by the effects of climate change (Boncour and Burson, in Burson, 2010, p 11). It may be that at some point in the future the Cartaret Islanders find their land more permanently uninhabitable, and need to move again. The cyclical nature of the Cartaret Islanders' migration shows that movements are not permanent, simple or related to climate change. Other resettlements related to environmental degradation, sometimes of whole communities, have taken place in Kiribati, Fiji, and the Solomon Islands, to name a few (Bedford and Bedford, in Burson, 2010). 
The Pacific is often pointed to as containing states likely to be affected by climate change-related migration in the near future, if migrations such as those mentioned above are not already linked to the effects of climate change. Containing many small island states with fragile ecosystems and human resources, compounded by geographical isolation (not to mention being particularly photogenic), the Pacific is in some senses an ideal poster-child for the potential problem of climate changerelated migration. Migration within the Pacific in relation to environmental factors is not a new phenomenon, but climate change and socio-economic issues have contributed significant additional challenges. "Climate change has the potential to affect almost every issue linked to poverty and development in the Pacific. It is also likely to exacerbate the vulnerabilities of already marginalised sections of society, including women and indigenous communities, and threaten the sustainability of traditional subsistence lifestyles. The impacts of climate change, therefore, must be seen in the context of existing poverty and vulnerability in the region" (Burson, 2010, p. 63).

Barnett and Chamberlain suggest that in influencing a decision to migrate in the Pacific, “...social processes that create poverty and marginality are more important factors than environmental changes per se" (Barnett and Chamberlain in Burson, 2010, p. 51). This is a crucial point to keep in mind when considering approaches to climate change-related migration, particularly in conjunction with development assistance programmes and immigration policies. New Zealand's geographical proximity, strong historical ties to the Pacific and its people (including former and current constitutional relationships with the Cook Islands, Niue and Tokelau), and socio-cultural similarities place it in a strong position to be instrumental in developing policies, in conjunction with the Pacific, to address the conglomeration of factors that can precipitate migration. The contribution could well range across international negotiations around agreements to deal with environmental migrants, through regional agreements, and into the current UNFCCC negotiations dealing with emissions reductions. 
Current media perceptions of the issue of climate change and migration neither particularly constructive nor informative for developing an approach to the issue, having a tendency to sensationalist thinking. Adaptation as presented in recent media reporting comprises people packing their bags and hoping New Zealand or Australia will take them in. This presents migration as the only response to environmental degradation and sea level rise in the Pacific, and presents the Pacific people as subject to the whims of countries like New Zealand eventually deciding whether or not to accept their inundated people (Associated Press, 2010; Macey, 2009). Climate change is undoubtedly contributing to a number of environmental and other problems in the Pacific, but media coverage tends to overlook the interrelated issues discussed above, such as inadequate infrastructure and resource management.

The media's simplistic conceptualisation leaps a gap between doing nothing and departing en masse - a gap which is filled with a huge range of options for addressing the socio-economic, political and environmental issues which are contributing to environmental degradation in the Pacific. It also over-simplifies the relationships between climate change and environmental change, environment and migration, and human activity and the environment. Most importantly perhaps, assuming a worst case scenario is the most likely outcome for the Pacific Islands presumes that mitigation is inadequate, that adaptation either does not exist, or that it will not have any effect on the eventual outcome (for the Islands' environment) (Tevi, 2010).

\section{Migration theory}

Migration is often posed as a response to the negative effects of climate change and environmental degradation. Migration is widely held up as a policy response, but needs to be taken - as with climate change effects - in the wider context of the Pacific Islands' environments. Movement of people within and between countries is not a new phenomenon for the Pacific or its people, who have long travelled around the region for many reasons. There is ample evidence of migration as an adaptive 
response to environmental factors in the Pacific. As a strategy to cope with changing environmental factors and extreme events such as droughts, hurricanes, and flooding, Bedford mentions resettlement programmes of entire communities of IKiribati within their own country and in Fiji (Bedford, 2008; Campbell, 2010). Observers should not assume that migration in the Pacific has necessarily been a negative experience - in some cases, such as responding to environmental fluctuations, is has been shown to strengthen resilience (Barnett and Adger, 2003).

Understanding what relationship, if any, exists between environmental factors and migration requires an understanding of what lies behind peoples' decisions to move. In general, there are three broad categories of migration drivers - push, pull, and intervening or restricting factors, as described by Black et al:

“a) factors related to the region or country of origin, including political instability and conflict, lack of economic opportunities, and lack of access to resources ('push' factors); b) factors related to the region or country of destination, including the availability of employment and demand for workers, higher wages, political stability or access to resources ('pull' factors); and c) intervening factors that facilitate or restrict migration, including ease of transportation, family or social networks, government immigration or emigration policies, economic ties such as trade and investment linkages, or social and cultural exchanges" (Black et al, 2008, p. 11).

However, these drivers do not act as neatly on peoples' motivations as they be described. These factors may apply singly or together in a particular circumstance, acting to spur migration. The relationship between factors at both ends of the migration process is possibly the most important in determining why people choose to migrate. "...[C]lassic migration theory posits that people will move from poorer to richer regions or from places where there is population pressure on resources to places where there is not. Yet this does not tell us whether the 'push' of poverty, or the 'pull' of economic opportunity is more important, even though this may be critical in terms of understanding whether and how much climate change will 
influence drivers of migration" (Black et al, 2008, p. 11). Such theories are not as applicable to climate-change-related migration as they may have been for previous migration patterns.

Push and pull drivers precipitate two types of migration - internal and external. Internal constitutes the movement of people within a state's borders, and in the case of the Pacific this can include movement between islands or atolls of the same state. External is the movement of people across state borders. Recent research seems to provide evidence of both internal and external migration as a result of environmental factors, but on close inspection Black finds the academic case for environmental factors being the driver unconvincing (particularly the much-quoted Myers). The examples presented often skate over the numerous other factors that were taken into account in subjects' decisions to move, such as land inheritance rules and political influence. Quoted statistics often have enormous ranges for migration figures, for example twelve to twenty-four million, which sometimes do not take into account important statistical aspects such as population growth (Black et al, 2008, pp. 2-3). Black et al. also note that it is difficult to make statistical and causative judgements about the relationship between environmental factors and migration decisions due to sheer lack of information - "...where existent, databases are weak at best" (Black et al, 2008, p. 3).

Statistics detailing migration flows could help anticipate and prepare policies for managing migration flows at origin and destination, and adaptation policies in countries of origin. Black suggests that the best way to predict future migration flows is to identify the sensitivity of migration drivers to climate change and variability. However, Black acknowledges that there is usually an insufficient evidential base to make clear predictions (Black, 2001). In attempting to codify possible climate change-related migration, Barnett and Webber identify seven general types of migration, as follows:

1. international labour migrants

2. internal labour migrants

3. internal displacement 
4. international displacement

5. internal permanent migrants

6. international permanent migrants

7. relocation of communities.

Barnett and Webber's categorisation is useful for understanding climate change induced migration as they reflect that migration is not necessarily permanent - it is eminently possible for temporary migration to be an effective coping strategy. They suggest that the latter three categories of migrants are most likely to face the greatest risks to their livelihoods and rights through migration, and therefore are the most in need of protection and assistance from governments (Barnett and Webber, 2010). It is loosely these three categories that Hodgkinson, Burton, Anderson and Young seek to provide for under their proposed Convention.

\section{Human activity and environmental change}

While there is no doubt that Pacific small island states are by nature predisposed to being particularly vulnerable to climate change, positing the inhabitants as passive recipients of a bad hand is over-simplifying the situation. That would suggest that the people of the islands have no agency for managing these vulnerable environments, making neither good nor bad changes to their immediate environment.

The consequences of sea level rise fit broadly into three categories: submergence and flooding, salination of surface and ground waters, and morphological change such as erosion and wetland loss (Nicholls, 2003). Sea level rise has high potential impacts, including erosion and flooding of low-lying areas, salination of fresh water lenses, rising water tables needed for human and agricultural use, damage to coastal infrastructure, and damage to businesses, tourism, crops, soil productivity and burial sites.

Nicholls commented that, "...human-induced changes in coastal zones are widespread and often profound" (Nicholls, 2003, p. 7). Coastal erosion can be 
exacerbated by the use of beaches as a source of building materials, removal of mangroves and similar vegetation, and by a lack of building and planning regulation. High (and increasing) population densities put pressure on limited fresh water resources, land availability, and minimal infrastructure. A lack of basic infrastructure, particularly waste and sewerage, undermines local ecosystems and pollutes fresh and salt water (in addition to the associated health problems). In the case of Kiribati, "...sanitation methods including traditional defecation at the beach or in the bush and pit toilets are still the most frequent. Most human and solid waste continues to be dumped in open spaces and along waterfronts, and water catchments have been gradually overrun with housing in the absence of effective land-use planning and regulation" (Storey and Hunter, 2010, p. 173).

Pollution of fresh and salt water has flow-on effects on local agricultural and fisheries production systems, and also damages fragile ecosystems such as coral reefs. Damage to reefs has subsequent effects on fish stocks. Agricultural production system modernisation also increased vulnerability, as cash crops (monoculture) are less resistant than polyculture to extreme weather events and ecosystem changes, and are less effective at maintaining good balances of nutrients in soils. (Barnett and Adger; Storey and Hunter) Referring particularly to Kiribati, Storey and Hunter found that "[t]he impacts of unmanaged urbanisation, a continuing crisis of inadequate sanitation, a lack of solid waste disposal controls and ineffective freshwater management offer [compared to climate change] equal threats to sustainability, even if they proffer less 'sensational headlines'" (Storey and Hunter, 2010, p.167).

The combination of Pacfic Islands' land's natural state, weather process and human activity, in conjunction, render the Pacific Islands particularly vulnerable to climate change. Generally, the Pacific Islands have low levels of development, small-scale government sectors, industry, infrastructure, and adaptive capacity for dealing with the effects of climate change. In conjunction, there is a negative effect on countries' ability to act as fast and comprehensively as seems to be necessary to deal with the effects of climate change. There are also tensions between priorities, over time - for 
example whether to address immediate and longstanding development challenges such as health, education and basic infrastructure, or to focus on adaptation to climate change. There is an increasing awareness of the need to mainstream climate change policies into existing development programmes and policies, and more activity to this end.

Non-climate change-related priorities and challenges often have a negative impact on a state's ability to response to the effects of climate change as quickly and comprehensively as necessary. Development support and aid is provided to Pacific countries through bilateral channels (development agencies) and by nongovernmental and international organisations, to assist with developing sustainable and effective infrastructure to address existing development issues such as waste management and energy production. Development agencies and international organisations (such as the World Bank and Asian Development Bank, for example) bring particular focus and political agendas to bear in the implementation of their assistance, regardless of rhetoric around objectivity and country-driven strategies (Barnett and Adger, 2003). It is unsurprising that countries with low state capacity are inclined to tailor requests to funding rather than building strategies and then requesting funding. A focus on developing tourism and economic sustainability draws scarce local government attention and resources away from basic infrastructure and services. Comprehensive integrated policy should not distinguish between good development and good (or 'good') climate change adaptation (Barnett and Adger, 2003). In this context, climate change should not be seen as a separate challenge but an exacerbating factor.

The intensity and magnitude of the Pacific Islands' plight under climate change is not a foregone conclusion, and action by both the islanders and the international community can make a huge difference to the eventual situation in these countries. There is now a great opportunity to develop practical, flexible and feasible policies at local, national, regional and international levels. The islands' inhabitants may not have been part of the Industrial Revolution's climate degradation but should not buy into the international tendency to see Pacific Islanders through a lens of vulnerability 
which posits them as passive recipients of fate. Rather, they could take responsibility for developing their island's futures and protecting their environments (Barnett and Adger, 2003). To a certain extent drawing international attention to the potential problem of sea level rise leading to forced migration in the Pacific islands is empowering, demonstrating international-level promotion to attract money and development assistance to assist with adaptation, and, ideally, prevent the need to migrate at all.

\section{The adaptation - migration spectrum}

The spectrum of actions from adaptation to migration shows the range of options for responding to the effects of climate change. Migration is not the only response, and adaptation may in some cases reduce the likelihood of it being a necessary response, but in itself has a range of activities from (for example) sea wall extension to producing different types of crops and changing urban development patterns. Adaptation is vital not just to narrow the gap between effects and action, but also to as far as possible enable people to make choices about their own and their land's future, rather than reaching a situation where choices have been reduced to where to migrate. Migration as an adaptive response is generally viewed as a mix of a coping strategy, for example where it helps reduce the population pressure on an island's scarce water or land resources, and of a longer-term strategy.

Given the longevity of the problem of climate change and the consequences of adaptive actions like migration, it is vital that a long-term view of the issue and potential responses is taken - beyond political terms and even the lifetimes of those developing responses. Timeframes are very uncertain, despite the degree of committed global warming (Canziani et al, 2007, p. 68), and addressing climate change effects is not an issue that should be deferred into the next political cycle or further. There is also a considerable body of work showing that addressing the effects of climate change earlier is better and cheaper in the long run than delaying until the effects are more severe and widespread. (Garnaut, 2008; Stern, 2006) 
Migration is attractive in sounding like a simple and suitably distant solution to a complex and contentious issue, and also helpfully avoids the expense associated with adaptation of an island that may cease to exist or become uninhabitable after the next large storm surge, or earthquake (or passage of time and sea-level rise). However, migration en masse from a country (such as Kiribati) raises a host of side questions that are interesting focus of academics' and policy-makers' attention. These include issues of sovereignty, international law, economic rights to EEZ's resources, and the many socio-cultural and socio-political complexities associated with transplanting people into what may be an entirely new and in some cases possibly unwelcoming context (Barnett, 2003; Burson, 2010; Macey, 2009).

There is an opportunity for affected countries to work with neighbours and other states to develop mutually beneficial, practical policies to dealing with the effects of climate change and managing environmental protection, drawing on and including the work of international organisations and non-governmental organisations such as the Pacific Conference of Churches and the Pacific Islands Forum.

Broadly, there are two pillars on which climate change policy response frameworks are proposed - mitigation and adaptation. Migration obviously falls under the ambit of adaptation, which is a hugely broad term of reference covering options dovetailing with the development spectrum, and including migration.

The first pillar, mitigation, comprises human intervention to reduce the sources and/or enhance the sinks of greenhouse gases (Canziani et al, 2007). Mitigation is undoubtedly necessary in terms of preventing further future effects of climate change, but because of the longevity of carbon in the atmosphere, the world is already committed to a period of warming and effects regardless of current action even if all emitting stopped now. Mitigation in the Pacific relates primarily to renewable energy and avoided deforestation. Forests are an effective sink for greenhouse gases (as well as having wider ecosystem benefits), and the UNFCCC includes programmes to provide financial and other incentives for reducing deforestation in countries like Papua New Guinea (UNFCCC, 2010). 
For mitigation to have a significant impact on sea level rise and other relevant problems in the Pacific islands, the biggest emitters (the US, China, India, and the EU, among others) need to take significant measures to limit their emissions (Canziani et al, 2007; New Zealand Ministry for the Environment, 2010). Achieving this is an issue for another piece of work - well beyond the scope of this thesis. Mitigation is above all a long-term response, and, given our respective emissions profiles, not one in which New Zealand and the Pacific can on their own make an impact significant enough to affect sea level rise in the region.

The other policy pillar, adaptation, can reduce the impact of the effects of climate change and increase resilience in the future (UNFCCC, 2010 (a)). Adaptation encompasses a range of actions and should be an integral part of development activity in developing countries. In addition to the UNFCCC-led processes such as the Nairobi Work Plan and Cancun Adaptation Framework, there is a proliferation of agreements, statements and action plans for addressing climate change effects at local and regional level, including the Pacific Islands Framework for Action on Climate Change (SPREP, 2005). Adaptation actions that will have flow-on effects for land productivity, health, and water supply sustainability, for example improving sewerage and fresh water management infrastructure, could be of highest priorities for countries like Kiribati. In general, adaptation planning should avoid duplication of efforts, and therefore it is essential to scope what action and planning is already underway and look at potential for modification of existing systems before creating new (and potentially costly) systems (Eastwood, 2009).

The complexity of migration drivers themselves and the difficulty of creating a policy dealing with climate change migrants interacts with other factors such as the longterm, slow-onset nature of the problem and the general sensitivity of migration issues in the domestic political context. Currently, the evidence for New Zealand needing a specific climate change migration policy is not compelling. However, the issue is not going to disappear and it is worth considering whether there is a need for more reliable information and thinking about how states such as New Zealand can 
work together with affected states such as those in the Pacific to address the prospect of climate change-related migration, including working to create a situation where migration is not necessary.

\section{$\underline{\text { Regional and international approaches }}$}

\section{Human rights frameworks}

Existing human rights norms and mechanisms will be broadly applicable to potential climate change-related migrants. However, they were not established with such migrants and situations in mind, and therefore there are aspects that may not apply as neatly as to other situations. One of the issues most exercising academics looking at possible approaches to dealing with the potential for climate change-related migration is statelessness. Whether a country is no longer a state when it is inundated or rendered uninhabitable is a matter of international legal debate. In terms of responsibility to protect rights this is related to the obligations of the state whose population has largely migrated - can the state, and by extension its people, still be said to have rights over their Exclusive Economic Zone, is the state still responsible for peoples' rights even if they have migrated to another country, what political and fiscal relationship exists between the state on remaining land and its people offshore ${ }^{1}$ ? Although it is important in the wider context of climate change migration, detailed discussion of the issue of climate-change-related statelessness does not fall within the scope of this paper.

Peoples have rights even if they move from their homes, and they also have an additional set of needs directly related to their migration, which may require assistance and support in addition to the protection of their rights. External migration (across state borders) in particular is an expensive process, and there are obvious potential issues related to establishing a new life with which migrants may need assistance. These could include financial or logistical assistance to move, support to maintain their cultural and social ties, and so on. The burden of

\footnotetext{
${ }^{1}$ For example, the 1,500 inhabitants of Niue can vote. The 20,000 Niueans in New Zealand have no means of political representation or influence on the island or its government. Niue could be an interesting test-case for climate change migrants wanting to maintain political involvement in decision-making about their island's future.
} 
responsibility for climate change - excessive greenhouse gas emissions - is often seen as imposing a corollary obligation to protect and support those forced to move because of it $^{2}$.

(As discussed in Section A, it is important to remember that 'climate change refugee' and 'environmental refugee' are terms with no legal basis under international law regardless of how many people use them. Quite apart from the lack of legal recognition, there is rising opposition to such terms among those who have the potential to become climate change-related migrants (Macey, 2009; Barnett, 2003)).

\section{Pacific initiatives}

The Pacific, as a region and through specific states with a vested interest in this area, has become the forum for frequent discussions on dealing with the effects of climate change and the potential for related migration at some point in the future. In the absence of a suitable policy space for climate change migration, Boncour and Burson recognise that "...a window of opportunity exists to place the human mobility and humanitarian consequences of climate change at the heart of the international policy debate on climate change. We hope the peoples of the South Pacific can be part of shaping this discussion" (Boncour and Burson, in Burson, 2010, pp. 10-11). However, policy development on such a broad, complex, and potentially sensitive international issue as this will necessarily be a labour-intensive and resource-heavy task if it is to be comprehensive and effectively linked to other policies, organizations, and regional or international schemes that may develop. In this sense, Pacific states can be at a disadvantage due to their size and resource availability.

\footnotetext{
${ }^{2}$ This idea is called 'historical responsibility', and is generally used in various contexts (aid, negotiations, climate change politicking) to make the case that the developed world should cover the costs of adapting to and mitigating climate change. However, 'developed' and 'developing' is not always as clear a division as it seems standing at either end of the spectrum. For example, Singapore is a 'developing' country under the UNFCCC, listed in Annex II; whereas if the measure of development were based on GDP Singapore would sit well within the 'developed' group of Annex I countries. Furthermore, New Zealand was hardly a heavily industrialised and polluting country during the $19^{\text {th }}$ and $20^{\text {th }}$ centuries, and China now leads the US in rate of emissions. (US Energy Information Administration, 2010 - 'An atlas of pollution: the world in carbon dioxide emissions'.) The developeddeveloping nexus can be a dangerously complex generalisation in relation to climate change and historical responsibility, and can obscure more important issues like vulnerability and adaptive capacity (which can include things like the amount of land available, human resources, and land infrastructure).
} 
However the pertinence of these issues ensure that climate change is a frequent issue for discussion within Pacific groupings, and its prominence is also increasing at wider international discussions. There have been a number of important and fruitful discussions within the region, and notable instances of drawing attention to the issue on an international scale, as follows. In 2007 the Pacific countries were instrumental in facilitating a UN Security Council Debate, and subsequent General Assembly Resolution (UNGA A/64/281) on climate change and security. New Zealand Permanent Representative H.E. Rosemary Banks delivered a statement to the UNSC in support of the resolution, which recognized the particular vulnerability of Pacific Island countries to climate change and the threats it poses to their environments and the viability of societies. Importantly, the New Zealand statement also recognized that assistance from the international community "...needs to be sufficiently nuanced to allow for different risk and development circumstances and to various national contexts...[and] also support the objectives of recipient states in order to ensure local ownership [of adaptation] and practical results" (New Zealand, 2007). Two themes that New Zealand has consistently supported through the UN and many other parallel processes such as the Pacific Islands Forum (PIF) are encouraging flexible support and policies to fit different Pacific (and international) contexts, and country-driven policy development and ownership (Eastwood, 2009; Plume, 2009).

Signed in August 2008, the Niue Declaration was the first comprehensive PIF statement on climate change, and laid out the key issues for and challenges faced by the region, acknowledging the particularly vulnerable situation of many of its countries. This Declaration also makes specific mention of the possibility of climate change migration, encouraging "the Pacific's Development Partners to increase their technical and financial support for climate change action on adaptation, mitigation and, if necessary, relocation" (Niue Declaration, 2008). It also encouraged Pacific countries to act with the assistance of partners to address pressing issues and build capacity and resilience. The Declaration is also important in that it specifically refers to the Pacific peoples' ambition to live in their own homes, insofar as possible. 
In the 2010 PIF communiqué, climate change warranted a 13-point mention, second only in priority to achievement of the Millennium Development Goals (Pacific Islands Forum Communiqué, 2010). In November 2010 a number of Pacific countries (Australia, Fiji, Kiribati, The Maldives, Marshall Islands, New Zealand, Solomon Islands and Tonga) adopted the Ambo Declaration at the close of the Kiribati Climate Change conference (the US, UK and Canada were observers). This Declaration included a specific reference to climate change migration, but interestingly, narrowed the field of reference to migration "...as a result of adverse effects arising from climate change extreme events" (Ambo Declaration, 2010). Theoretically, this rules out migration as a consequence of sea level rise or other gradual processes such as declining rainfall or decreased availability and quality of fresh water. It is also silent on what constitutes 'climate change extreme events' - given the difficulties of attributing an event such as a cyclone or flood to climate change, such a narrow definition seems potentially short-sighted. On the other hand, a definition referring to 'the adverse effects of climate change' would be broad enough to encompass the myriad climate change effects discussed above that could precipitate migration. However, the Declaration does not bind states to any actions, so the specific formulation of the definition is only of academic interest, unless it is later picked up by more active agreements.

These documents are only a sample of the work the Pacific countries have undertaken with partners in the region and further afield to draw international attention to their needs and develop suitable adaptive responses, integrated with development planning and assistance. It is interesting to note that there is little mention of the local and human activity factors causing degradation in such documents; the focus is solely towards "external" climate change-caused problems. Integration with current development plans is a slight nod to this relationship between causal factors. 
The potential and possibly distant nature of climate change-related migration does not mean that states' policy frameworks do not include any aspects that could accommodate climate change-related migrant, such as existing migration policy. However, states are also the subject of some pressure to create specific policies, thereby setting a precedent for future cases of climate change-related migration.

For example, suggestions can include a charge that New Zealand and Australia should take the lead on developing an approach to dealing with (supposedly inevitable) migration from the Pacific (Coates, 2010). This stands in direct contrast to the views expressed by groups such as the Pacific Conference of Churches, which urges the Pacific countries to find their own solutions and address the myriad of issues around environmental degradation and migration, with support from New Zealand and Australia, but not necessarily being led by others to a solution not of the Pacific's making (Tevi, 2010). New Zealand and Australia certainly have an existing and continued role in facilitating and joining discussions and assisting islands (through existing packages of aid) to work at this themselves, and the Pacific countries have an interest in helping each other to make the most of their relatively scarce resources.

Climate change has drawn attention to the Pacific in a way possibly unprecedented by anything other than nuclear testing. Kiribati and Tuvalu have become posterchildren for climate change-induced sea level rise, and the effects of the developed world's excess on the developing world and its pristine idyllic environments (Gemenne and Shen, 2009).

Many media articles and some academic works contain assertions, mysteriously uncited, along the lines that New Zealand has been asked, is negotiating to, or has offered or refused to take in climate change migrants from Kiribati and Tuvalu. The most well known reference was Al Gore's in 'An Inconvenient Truth' (David, Bender Burns and Skol, 2006). In all its forms, this assertion appears to be largely untrue. While there have been suggestions by various countries and organisations that New Zealand would be a likely candidate for migration from the Pacific countries for the 
reasons above, thus far none of these suggestions constitute a formal approach by a Pacific government to the New Zealand government to which a clear "yea" or "nay" would be given (Barnett, 2003).

New Zealand has development, climate change and migration policies related to the Pacific but the migration policies are not specifically designed to accommodate climate change migration, and development policy does not include specific attention to migration (Dunstand and Canham-Harvey, 2009; Eastwood, 2009; Barnett and Webber, 2009). New Zealand currently has two migration policies that enable Pacific people to come to New Zealand: the Pacific Access Category, and the Recognised Seasonal Employer (RSE) policy. The former allows for 250 people from Tonga, 75 from Kiribati and 75 from Tuvalu to gain residence in New Zealand each year, under a ballot system. The RSE policy is a "...circular scheme for temporary work", and each year around 8,000 seasonal workers, predominantly from the Pacific, come to New Zealand to work. However, the Department of Labour, which is responsible for migration policy, states that "New Zealand has no immigration policies presently that respond directly to climate change. This does not preclude policies being developed in the future, but there is currently no mandate to do so" (Dunstand and Canham-Harvey, 2009).

\section{The United Nations Framework Convention on Climate Change (UNFCCC)}

The United Nations Framework Convention on Climate Change treaty was established to consider what could be done to address the effects of and reduce global warming. Now with 194 State Parties, and the related Kyoto Protocol (which has stronger, legally binding measures to reduce emissions but a smaller membership of developed countries covering fewer emissions), negotiations are continuing to achieve legally-binding commitments to mitigation targets which will hold global warming at 2 degrees Celsius (above pre-1990 levels). The UNFCCC and its subsidiary bodies (the implementation arms) also provide a plethora of assistance mechanisms and support to developing countries to assist with adaptation to the adverse effects of climate change (UNFCCC, 2010). 
Small island countries have formed a group to represent the interests of those most vulnerable to climate change, particularly sea level rise, at the UNFCCC negotiations - the Alliance of Small Island States (AOSIS). The group includes the Maldives, Pacific countries, and Caribbean states.

At the international level, the UNFCCC specifically covers migration in its latest iteration (the 'Cancun Agreement', which is still the subject of negotiation), calling on Parties to enhance action on adaptation under the Cancun Adaptation Framework, including " ...measures to enhance understanding, coordination and cooperation with regard to climate change induced displacement, migration and planned relocation, where appropriate, at national, regional and international levels" (UNFCCC, 2010).

While it is useful to have the migration point specifically made, it is made fifth of eight in the decision and follows adaptation actions, which would preempt migration being necessary, including strengthening of infrastructure and building resilience to the future effects of climate change. Complementary to the UNFCCC, Boncour and Burson suggest that the successor agreement to the Kyoto Protocol should explicitly recognize human mobility and humanitarian consequences of climate change at the heart of the document, directing the international response to climate change (Boncour and Burson, in Burson, 2010).

\section{Other initiatives and approaches}

Outside the Pacific, much further investigation work has been done by international organizations and academics, including the UN University, Asian Development Bank, World Bank, OECD, Refugee Studies Centre, and International Organisation for Migration, among others. By and large, these studies have thoroughly covered the ground of causality, the legal frameworks around definition and whether the concept of "refugee" and existing international law are adequate. They have also skirted the issues around prediction of likely numbers, statistical information and difficulties around attribution to make judgements (as is their prerogative). 
All investigation agrees that the issue of climate change migration is very complex and urgently needs attention from the international community of states, as well as country-specific, detailed information-gathering to enable development of suitable country-led responses. Many investigations also draw attention to the social and economic aspects of migration, and the need not just to address the cause and physical move in itself, but also ensure that systems are in place to support migrants throughout their move and resettlement. (Some also pick up on the need for choice and potential for moving back and forth, and importantly for not moving as an option, regardless of the likelihood of inundation).

However, the work of organizations thus far mostly sets a scene for thinking about climate change migration, and notes that more specific information is needed on country-level movements and inclinations. Few outside the academic world have proposed practical steps and attempted frameworks that could usefully be picked up by domestic policymakers and the international community. Barnett, Bedford and Burson all make policy suggestions for New Zealand, and Hodgkinson, Burton, Anderson and Young hope to draw states' attention to and support for their proposal, which provides an institutional and theoretical structure that could be taken up and developed by countries into an international instrument, possibly under the auspices of the UN (Bedford, 2008; Barnett, 2003; Burson, 2010; and Hodgkinson, Burton, Anderson and Young, 2010).

Hodgkinson, Burton, Anderson and Young recognise that other proposals addressing climate change migration proffer parts of the solution but do not provide a comprehensive solution. Their Convention examines 5 substantive proposals (including one of their own earlier iterations) and finds that none has "...offered a comprehensive, global solution to the displacement problem; our proposal, which builds on our earlier 2008 study, attempts to provide such a solution." Briefly summarised, Willams' proposal promotes the development of regional agreements under an international framework agreement; Biermann and Boas' work proffers a 
protocol to the UNFCCC; and the proposals of Docherty and Giannini, and Hodgkinson, Burton, Anderson and Young's 2008 study promote global, standalone agreements.

Docherty and Giannini's proposal only provides for people displaced across state borders, thereby not addressing the significant likelihood of high volumes of internal migrants. Betaille et al. focus on environmentally displaced people, which is a broader catchment than Hodgkinson, Burton, Anderson and Young see as needing immediate attention. Willams proposes the development of regional agreements under an accord linked to the UNFCCC as part of a post-Kyoto compact. While the period covered by the Kyoto protocol will soon come to an end, negotiations of a successor agreement are moving slowly. With the statements by Japan and others that they will not sign up to a second commitment period of the Kyoto Protocol, the future of a successor agreement looks more likely to sit within the UNFCCC itself.

International environmental accords are at the mercy of states' willingness to adhere to them. Williams thinks that concerns around state sovereignty would preclude success of an international agreement. This seems a rather spurious argument, given that state sovereignty has not prevented the agreement of many other international agreements with similar intrusions into a state's affairs - and state sovereignty is an issue that would necessarily be worked through in the drafting of any agreement. Hodgkinson, Burton, Anderson and Young manage the issue by weaving the primacy of the state into their proposal, and no doubt were their proposal to come up for negotiation there would be more discussion and framing of the issue. 


\section{Section C}

\section{Gaps in current initiatives and approaches}

This section examines the underlying assumptions inherent in discussion of potential climate change related migration, that because there is no specific mechanism to address climate change-related migration specifically that the perceived gap must be filled. It is asserted that many factors likely to contribute to the need to migrate, such as environmental degradation and lack of economic opportunity, are dealt with through other mechanisms and arrangements. Further, that creating a specific climate change-related migration mechanism could disadvantage those affected by problems that are not obviously linked with climate change. This section questions the presumption that climate change-related migrants should be prioritized above, for example, economic migrants. It addresses the political aspects of the debate around potential climate change-related migration and considers the symbolic role the image of small island states has come to have in framing the debate and approaches.

Despite approaches which have been developed and nascent initiatives as discussed in Section B, gaps remain in the possible approach to potential climate changerelated migration at the international level. There is no climate change migration equivalent to the Refugee Convention to draw all the disparate elements together, and it seems unlikely that the UNFCCC will increase the prominence of the issue to the extent that is called for by Barnett, Boncour and Burson, Bedford, the International Organisation for Migration, and others. "While existing international humanitarian, human rights, and refugee law gives rise to obligations towards some of those who may be displaced or migrate from climate change, there are clear gaps in these international law protection frameworks" (Burson, 2010, p. 171). 
However, there is a widespread assumption that the gap means that climate changerelated migrants will not have any protection for their human rights, that they will be cast adrift and rendered stateless with no government or relevant international organization to protect them in theory. All people, regardless of their state or lack thereof, their migratory or sedentary status, or the label they attach to their type of movement, have their rights conferred and protected by the Universal Declaration of Human Rights (UDHR). However the current international system of states has shown that to have these rights protected and met one needs to have a formal attachment to a state.

It seems that in the case of climate change-related migrants, the concern is less the protection of peoples' human rights than the maintenance of their connection to a state (or two). The corollary concern is the flexibility of states' understandings of human rights to provide protection and assistance to deal with migration that stems from factors outside people's control, or partly outside their control (in the case of a mix of causal factors). If people move within a state, theoretically the state's protections continue, though they may be directly the subject of a different local implementing structure through another council or community. The tone of academic and other commentaries suggests a fear that people's movements will be seen as another movement from choice, rather than a process through which they should be entitled to assistance, as would be the case (or at least the expectation) with natural disasters.

Practically, the predominant issue around protection of people during movements related to climate change is as a result of slow-onset events. As New Zealand and Australia frequently demonstrate in relation to countries in the Pacific, when there is a natural disaster, assistance is provided. It is highly unlikely that such countries would suddenly cease to provide assistance when there is a need, or when a request is made, simply because the cause of devastation and distress occurs more slowly than typical natural disasters. 
That said, slow-onset events such as sea-level rise and changes to weather (e.g. rainfall patterns) or ecological balances (e.g. coral reefs and fish stocks, soil fertility) are dealt with through different mechanisms such as development assistance and budget support. Should climate change-related migration occur as a result of such effects, the established responses of neighbours may not be a given.

States are in all likelihood unwilling to create a precedent for adding to their burden of development assistance and contributions to international organizations. Small island states (SIS), with their small populations, typically established migration patterns to and agreements with other countries, are one question. Quite another question is the extrapolation of such a support expectation to populous and deltaic Bangladesh and India.

It is clear from the work of Bedford, Burson, and others that SIS are likely to be the test cases for development of responses to and human rights protections for climate change-related migrants. In both SIS and those such as Bangladesh and India, issues of expected response and precedent increase the necessity for understanding and practically applying the nexus between adaptation and migration, in part to try and avoid hitting the migration end of the spectrum.

It may be that states are hoping to avoid the necessity of dealing with large-scale, unexpected migration by dealing with adaptation and prevention in the interim, while trying to come to terms with whether there is in fact a need to develop a formal response to climate change-related migration. Migration is best conceived of in terms of an adaptive strategy, which would hopefully follow a number of other actions. There is consensus, on top of common sense understanding, that having to leave homelands and family because of climate change-related factors should always be voluntary, and preferably a last resort (although not necessarily at the last minute).

There could be (an understandable) disinclination among policy makers to create a separate issue from within its existing ambit. Climate change adaptation is a broad 
issue which has international attention and understanding, and is addressed prolifically in international agreements and regional activities (including bilateral development relationships). Creating a sub issue from within its ambit is something states (and other players) are reluctant to do. It could also have a negative impact on existing work to establish the need and responses to the effects of climate change and attempt to reduce emissions. Establishing as a separate issue could obscure the need to focus immediately on adaptation, and give a false impression that adaptation will not have any significant effect on factors leading to migration, so migration is inevitable.

Understandably, there may also be a prioritization of problems in the face of scarce resources, those most immediate and pressing being dealt with first. Issues such as dealing with changes to rainfall and fresh water availability may be the first changes noticed in some countries, and therefore garner more attention than migration or soil degradation, which are longer-term issues. Migration could be seen as a failure of states' action and of their responsibilities (under UNDHR) to meet citizens' needs. They would have failed in the UNFCCC's ultimate objective of enabling ecosystems to adapt. Many states would not want to be the first to be noticed and acknowledged in this group. With the increasing attention and understanding of the issue this is less likely, but there remains a possibility for a focus on adaptation rather than migration.

The President of Kiribati, Anote Tong, has been very open in the past few years about the need for his country to look seriously at relocation of some people in the short term (Tong, 2009). Tong has been noticeably silent on attributing blame for the situation deteriorating to this point, but it is clear that mitigation and financing to facilitate adaptive measures (including migration) in developing countries (particularly SIDS) must come from developed countries.

The strongest voice for the right to relocate comes from Kiribati, particularly in the short term. Most other small island states speak of climate change-related migration in terms of a longer-term development, which they are working to 
incorporate into the many other challenges they are facing and responding to with relatively limited resources. Understandably, the dire and dramatic nature of an expectation that your country will be submerged is a useful opportunity for littleknown states to gain attention on an international scale. The potential fate of small island states has propelled the issue of climate change-related migration above a small number of people on tiny islands in a neighbourhood that has largely kept to itself and managed its own business, onto a global stage and attention. With attention can come donor and other assistance. It is hard to argue against the rights of a few thousand people from Pacific Islands relocating to another island or country, but extrapolate those rights onto the population of Bangladesh or the Maldives, and some in the international community realize that more thinking needs to be done before taking action.

As discussed in section $A$, the effects of climate change are complex and often unpredictable, and migration itself is a very convoluted and sensitive issue. The nexus between the two involves an order of magnitude more complexity. Climate change and migration also fall into the category of what are now being known colloquially as the many 'climate change ands'. Migration is the 'and' that is probably more distant than many of the others, both in terms of direct impact on the lives of those in what would be host countries, and in terms of time, as migration may not be an absolute necessity in our lifetimes for most countries. As a 'climate change and' it has to jostle for status against similarly worthy issues which address other fundamental human rights, such as climate change and food security, or climate change and health.

An approach to whether there is a gap in existing approaches to migration and responses to the effects of climate change should also ensure that possible countries of origin are not given the impression that migration is their only option so that adaptation slides down in intensity. It is vital, as discussed above, that the people and governments of the Pacific Islands undertake adaptation to the adverse effects of climate change, with support and financial assistance from other countries, including New Zealand. Gemenne and Shen noted "...the constant characterization 
of Tuvaluans as potential environmental migrants, or 'refugees', can enclose them into a relativist trap and prevent them from developing adequate adaptation strategies. This categorization can also result in a loss of confidence" (Gemenne and Shen, 2009, p. 28).

Strategically framing the issue of climate change and migration to ensure adequate attention to and action from international and domestic communities is a problem for its proponents. While the need to get traction on some sort of approach may be obvious and deeply pressing for some people in the government of Tuvalu (for example), governments are always facing issues such as natural disasters, financial crises, and political challenges that require more immediate and decisive action than a distant potential problem. The government of Tuvalu may also be looking at the need to improve roads and access to healthcare for rural communities rather than address the effects of climate change. The international community is often diverted from long-term, less dramatic problems by those of short duration and high impact such as earthquakes in Haiti or Japan, and rebellion and government atrocities in the Middle East, with their associated effects for the global economy and oil supply. Nonetheless, climate change and migration will resurface and the calls for an approach to be developed at the international level will return.

There are various potential fora for dealing with climate change migration at an international level, within an organized, state-centric arena. The obvious contenders are the UNFCCC and Refugee Convention. The former is often suggested as a 'home' for climate change migration issues, or that at the least any mechanism developed should be linked to the UNFCCC (Hodgkinson). The UNFCCC's raison d'être centres on making high-level changes to country behaviour, constructing a framework within which implementation actions take place at country and regional level.

An attempt to prioritise climate change migration over other climate change issues (such as financing for adaptation or acceptable mitigation commitments in the UNFCCC) may in fact backfire, by precipitating a period of negotiating over priority of issues, and weaken the UNFCCC's focus by proliferation of subject matter and 
negotiation rivulets rather than creating a strong 'home' within which climate change migration can be dealt with. While there are obvious reasons for avoiding duplication of effort and spawning of climate change-related organizations, in the case of climate change migration it makes most sense for a discrete consideration, albeit linked in to the UNFCCC in some way.

However, the existence of an organization with 'UN' and 'climate change' in its name does not necessarily equate to it being the most appropriate organization for dealing with climate change-related migration. The UNFCCC has a specific focus, on managing emissions, and while its ambit is broader than just mitigation, states should be wary of encumbering it with tasks better managed elsewhere or under another organization. To use the example of another organization with a broad ambit, the Food and Agriculture Organisation is not asked to deal with faminerelated migration, so why is the UNFCCC looked to for managing climate changerelated migration?

It is interesting that no commentators seem to have suggested establishment of a 'migration organisation', for example. Given the complexity of factors involved in migration decisions and the increasingly global nature of peoples' movements, it could be useful.

Such an organization could also manage the needs of those who are forced to migrate in whole or in part because of economic hardship, which is, like the effects of climate change in many cases, not of their making. In the wake of the financial crisis, and with the decline of many European economies and possibly even the Euro, many Americans and Europeans found themselves jobless and homeless, or had livelihoods have been ruined by war. Those who were directly affected and have to migrate are affected by a problem with human causes, but the international community is mysteriously silent on the need for an organization and funding to support economic migrants.

The Refugee Convention confers a set of rights that helpfully provide a base on 
which climate change migration approaches could be built, and sets a possible standard formulation for developing a specific document for dealing with the issue. However, as mentioned in the discussion of an appropriate definition for climate change migrants, 'refugee' is a specific tag that is well understood and over time has developed clear parameters and appreciation in the international community. Modifying the Refugee Convention to broaden its scope is not necessarily a sound idea in terms of maintaining the clarity and strength of the concept for refugees. Arguably, it is also easier to see the link between life-threatening political or religious persecution and the need for migration - a link that is not always so obvious in the context of environmental degradation.

Combining refugees and climate change migrants under the umbrella of the same set of arrangements or convention could possibly be offensive to the latter, who may feel that they are being framed as victims unable to address their situations. It could also be offensive to the former, who are persecuted or fear death and are forced to migrate on those grounds. 'Refugee' holds connotations of becoming stateless, of cross-border movement, of an urgent need to leave a homeland, usually permanently and swiftly - and none of these situations necessarily follow climate change related environmental degradation. Painting potential climate change migrants as refugees by including them under an expanded Convention may seem a good way of utilizing existing international instruments to deal with new problems, but would do them a disservice in narrowing the scope with which the international community, and potential host countries and communities, would view their situation. The definition of a refugee and associated possibility of using refugee status to build a new life could be diluted if the lie of the land changes, not to mention the increased pressure of more people funneling through refugee processing centres.

Any international framework created or modified to accommodate potential climate change migrants should include enough scope and flexibility to enable migrants to develop a path of their choosing, should it be necessary to move at some point in the future. While difficult, it would also be best if the framework was also 
sufficiently flexible to accommodate dynamic patterns of migration and changing scientific projections of the effects of climate change. The future is by and large unknown and creating an overly restrictive and rigid framework could potentially render it useless for some groups of climate change migrants. It is possible that an inadequate or restrictive framework could send a message that climate change migrants are already catered for in the international system and therefore bilateral or other arrangements are not necessary, or that they are trying to buck the system by going outside the framework. Establishing a system that duplicates or cuts across existing rights frameworks (such as the UNHCR or rights established under existing bilateral agreements like New Zealand's RSE scheme) could be equally damaging. This is not to say that the framework must be written with reference to all relevant existing domestic policies, but rather that it must retain a degree of flexibility.

Flexibility will also be important to accommodate different types of climate changerelated effects and migration. For example, those who could be termed 'water migrants' in a response framework may draw to mind delta or small island-dwellers whose land and homes have been inundated, but there are also likely to be droughtrelated migrants. Both situations can be (partly) attributed to the effects of climate change, but the circumstances around the cause and effect and movement are very different. The international community is also likely to respond differently to the two types, depending on whether one attracts international attention as a crisis requiring an emergency humanitarian response.

As most argue, climate change migration will work best when it is part of a planned series of adaptation actions, rather than an ultimate last resort outcome (Barnett, 2003; Burson, 2010). Much work is underway internationally, regionally and incountry for bringing adaptation planning and action into the mainstream policymaking and work of governments. There is broad agreement that this is an important and necessary step, given the extensive overlap between development and adaptation - many actions working on the same problem under what are potentially separate funding and planning streams, such as water management which is climate change-related via rainfall patterns, and health related via quality 
and supply relative to population (Eastwood, 2009).

Ideally, adaptation actions (such as reducing or preventing rebuilding and new building in coastal areas likely to be inundated or flooded) will reduce the need for people to move internally and externally. However, it is clear that at some point people will need to move for various reasons, including climate change, and that governments have to find a way to adjust their policies to ensure that they can accommodate these people. An international institutional framework will have a role to play in that. There is certainly broad assumption that a mechanism at the international level is needed (Hodgkinson et al, 2010; Barnett and Webber, 2010; Black et al, 2008; Barnett and Adger, 2003).

\section{Summary of gaps}

At present there is no international arrangement operating that oversees climatechange-related migration internally or externally. The issue is conveniently being dealt with on an ad hoc basis, if movements are defined as being the result of climate change migration. Although New Zealand government policymakers currently have no mandate from the government (Dunstand and Canham-Harvey, 2009), New Zealand would want to approach the issue of climate-change-related migration with our specific context in mind. There have been some studies of migration flows between the Pacific and New Zealand, but researchers concurred that there are difficulties in establishing that climate change is the cause of people's decision to move. They also identified that with the surge of interest in climate change and the Pacific, survey participants were getting less interested in participating in studies (Burson, 2010; Barnett, 2001).

In formulating policy a government would need to obtain a clear scope of the scale of likely migration, in relation to population growth compared to external migration. In the case of the Pacific and New Zealand, for example, Gemenne and Shen's EachFor project in 2009 looked at current migration patterns between Tuvalu and New Zealand, and found that contrary to the frequent portrayal, migration is not usually about environmental drivers; and importantly (and in common with Barnett), 
that views on migration within Tuvalu are complicated. "Overall, migration from Tuvalu to New Zealand is not as straightforward as it is often presented. Views on the role of climate change in migration in Tuvalu remains [sic] contrasted and sometimes conflicting, while the motives of those who emigrated to New Zealand were not merely environmental, but included economic and social factors as well" (Gemenne and Shen, 2009, p.27).

Burson has obtained the most comprehensive data for Pacific - New Zealand climate change-related migration thus far, and the next step would probably be to look at New Zealand's existing policies to see whether there is room for flexibility to accommodate urgent migration while longer-term policies are developed (Burson, 2010). This is the approach promoted by Bedford, who also indicates that a suite of policy options needs to be available (Bedford, 2008). One component of that suite is an international-level discussion, and possibly an institution.

\section{Mechanism justification}

Throughout discussions on climate-change-related migration, including this thesis, there is a latent assumption that an institution or mechanism at the international level is necessary to deal with possible climate change migration, with all its causes, complexities, and forms. The base of this assumption rests on two premises: first, that we must protect the rights of others, which are threatened by climate change, and second, that existing rights regimes do not sufficiently deal with climate change migration. "There can be little doubt but that climate change-related events and processes, in all likelihood, will substantially interfere with the enjoyment of fundamental human rights by millions of people" (Burson, 2010, p. 162). But we should not leap to conclusions about the necessity for an international instrument as the best means for protecting the rights of migrants.

Burson argues that an international instrument alone is not enough to adequately address the rights of migrants, and that policy-making and implementation has an important role to play in protecting the rights of climate migrants. "...[C]laims for protection will need to be dealt with in the policy sphere, not the international law 
sphere" (Burson, 2010, p. 172).

Non-existence of a specific regime is not a sufficient reason to create an international mechanism. With climate change as the issue du jour, and one which has the potential to affect so many lives so deeply, there is an attempt to assume the best way to deal with climate change's effects is to create institutions. Policymakers at national levels and states at regional and international levels must resist this temptation. The effects of climate change are multitudinous and complex, and trying to create institutions to deal with specific aspects of these risks oversimplifying the problem. Policy makers should beware of creating institutions for every aspect of new problems, as they could make the issue of climate change seem fragmented and perhaps not as viable: disparate pieces brought together without necessarily having a prior relationship until the advent of climate change.

While international mechanisms for the protection of human rights exist and are well-known, the Office of the High Commissioner of Human Rights reported that the current protections under international law do not adequately provide for some of the categories of people likely to be displaced by climate change (OHCHR, 2009, p. 19). However, this is not to say that the rights of climate change migrants dissipate as soon as they make a move. "That there are gaps in the existing protection regimes does not mean those displaced or migrating are devoid of any rights protection ... under general multilateral human rights treaties such as the 1966 ICCPR and 1966 Covenant on Economic Social and Cultural Rights, states already have obligations to respect, protect and fulfil the rights contained therein of people within their jurisdiction. That these people migrate or are displaced by climate change to within the state's jurisdiction does not divest them of the rights they enjoy" (Burson, 2010, p. 169).

General consensus among practitioners working on the issue of climate change migration is that the Refugee Convention is inappropriate as a specific protection for climate change migrants (Hodgkinson, Barnett, Burson). These practitioners consider that, while not ideally suited, the UNFCCC is the obvious existing instrument 
dealing with climate change and all its aspects. They suggest that devolving migration and other adaptation actions from it could weaken the UNFCCC by making it seem that it is not an appropriate home for issues not directly related to weather and climate, whereas all related issues should be tied to the organisation.

There is no doubt that there is a strong potential for climate change-related migration that needs to be considered, and in turn the need for an effective response also must be considered. However to fully and productively justify the creation of a mechanism to deal with climate change-related migrants, we must be very clear how these people are different from those in a situation also not of their causing but a consequence of human activity. We risk creating a precedent that could undermine the importance of what is to be addressed. 


\section{Section D}

\section{The proposed 'Convention for Persons Displaced by Climate Change' as a possible solution to identified gaps}

The proposal for filling the perceived gap is described and analysed, with a view to assessing whether it addresses the points raised in Sections B and C. This section considers whether a proposed convention makes a valuable contribution to the debate and potential approaches. It argues that these authors also presume a gap that needs filling by a mechanism, and set out to create a practical framework for managing potential climate change related migration. It argues that the Convention's predominant value lies in its creation of a practical organisational structure.

The section identifies various aspects of the proposed Convention which could be modified to better address the potential problem, taking into account issues examined the preceding sections. The thesis argues that the Convention adopts a simplistic approach to supposed 'responsibility' for climate change and the associated duty on those deemed responsible to financially mitigate its impacts and address effects such as migration. This section argues that the Convention may be theoretically sound, but if it is to have a useful and practical applicability it must be politically feasible. In its current formulation aspects such as definitions and funding apportionment are very likely to make it unpalatable to the international community 
of states. The requirements for immediate funding and practical assistance are limitations.

While the singling out of small island states or a specific section is laudable in relation to the political weight, in the wider context the current section as written would be more appropriate for a regional rather than international mechanism. The Convention establishes a useful set of principles for which there may be broader application as approaches to the problem continue to be considered.

\section{The proposed Convention}

A group of academics working on climate change-related legal matters in Australia have undertaken a considerable amount of work on issues around the possible legal consequences of climate change, and their latest project was to draft a proposed Convention for dealing with the possibility of climate change-related migration. Hodgkinson, Burton, Anderson and Young's proposal is called "The Hour When The Ship Comes In: A Convention For Persons Displaced By Climate Change", and will hereafter be referred to as 'the proposed Convention'.

The possible problem of climate change-related migration has the potential to involve a vast number of individuals and states across the world, depending on the severity of the effects of climate change and the actions people take to deal with those effects. In that sense, it is not necessarily fair to require the authors of any proposals for dealing with the potential problem to hold any particular credentials or background - if they are to be affected, why should they not comment? However for the purposes of this thesis, it is useful to know a little about the authors of the proposed Convention, and their motivations for drafting it.

All four authors have a background in environment and legal matters, and are based in Australia. David Hodgkinson is a Special Counsel at Australian law firm Clayton Utz, an associate professor at the University of Western Australia Law School, a member of climate change and aviation advisors 'The Hodgkinson Group', and is Executive Director of Australian-based EcoCarbon (an industry partnership building 
capacity in market-based mechanisms to reduce greenhouse gas emissions (www.ecocarbon.org.au). Hodgkinson appears to have led the project and its limited promotion to date, supported by Tess Burton, Heather Anderson and Lucy Young. Tess Burton is a chapter author of Hodgkinson's publication Climate Change Law and Policy in Australia, and a research officer at the Victorian Parliament. Heather Anderson has worked on native land right issues in Western Australia and Victoria states, and is a law and arts student at the University of Western Australia. Lucy Young is the convenor for the Western Australia Environment Action Network, and is a solicitor with Western Australia Legal Aid. The four authors will hereafter be referred to as 'Hodgkinson, Burton, Anderson and Young'.

That the authors are all based in Australia, with its proximity to and strong relationships with the Pacific states, could account for the focus on small island states in the proposed Convention. Conspicuously absent however, are references to New Zealand, which is also highly likely to be a significant player in any climate change-related migration in the Pacific region (through political and historical relationships, existing migrant communities, as donor or host).

Through their work on the proposed Convention, Hodgkinson, Burton, Anderson and Young identify a gap in the existing human rights protection mechanisms, which would disadvantage potential climate change-related migrants. They suggest that the existence of the gap in itself is justification enough for creating a filler. They extrapolate this as an opportunity to take their existing academic and publicising work further, creating a framework for the practical management of potential climate change-related migration. They hope that the framework will be adopted by the international community of states managing the migration process and envisage that it would ensure that the human rights (as understood in the Universal Declaration of Human Rights) of climate change-related migrants would be comprehensively protected.

Hodgkinson, Burton, Anderson and Young's stated purpose is that the proposed Convention "...provides a general framework for the provision of assistance to 
climate change displaced persons ${ }^{3}$ [sic] [CCDPs] (regardless of the nature of their displacement), ... address[es] gaps in existing protections by setting out a framework for the protection of those persons displaced across international borders, as well as identif[ies] principles which should apply to the resettlement of persons from small island states" (Hodgkinson, Burton, Anderson and Young, 2010). Their starting points are recognitions that a lack of coordination among governments creates a gap, and that pre-emptive organisation of migration is the best approach to avoid "inconsistency, confusion and conflict". (Ibid, p.3) Finding that current international law protections and climate change-related agreements (primarily the UNFCCC) do not cover climate change migrants, the proposed Convention aims to "...address gaps in the international regime of human rights protections and humanitarian assistance as it currently applies to CCDPs" (Ibid, p. 9). The authors describe their Convention as the "...most effective way of resolving this problem" (Hodgkinson, Burton, Anderson and Young, 2010, p.3).

Set firmly on a base of state-centrism and existing mechanisms, the proposed Convention intends to provide a framework for protecting the rights of and a mechanism for providing assistance to climate change-related migrants and their hosts, and to establish a set of principles to guide the management of movement of people from SIS. SIS are prioritised under the Convention, on the basis of severity of climate change effects on their environments, the short timeframe for addressing the effects of climate change, and despite this small proportion SIS inhabitants of likely climate change-related migrants worldwide. The Convention sets principles for application to bilateral agreements, which are to be negotiated under the aegis of one of the Convention's implementing bodies - the (Climate Change Displacement Organisation (CCDO). The Convention provides only for movement from developing to developed countries. The implicit assumption seems to be that developed

\footnotetext{
${ }^{3}$ For clarity, I will retain Hodgkinson, Burton, Anderson and Young's usage of 'persons' although it is never made clear what, if any, distinction is drawn between 'persons' and 'people' that resulted in the latter being ruled out for use throughout the Convention. This may seem to be grammatical quibbling, but the proposed Convention refers to the migration of groups en mass - presumably 'people' in the sense of a community, whereas 'persons' is likely to be colloquially understood as connoting individuals. The issue here is whether the authors intend us as readers to understand the subjects of the Convention as individuals or groups (e.g. communities), in the context of climate change-related migration.
} 
countries and their citizens are able to take care of their own who may become climate change-related migrants without needing recourse to an international mechanism.

Part of the value, and certainly the uniqueness of this proposal, lies in its creation of a detailed organisational structure to implement the proposed Convention. As the authors point out, other proposals describe the administration but do not detail the operational arms of an instrument. Hodgkinson, Burton, Anderson and Young's Convention has the following governance structure. It is headed by a Climate Change Displacement Organisation (CCDO), which comprises four bodies, and its functions are demonstrated in the diagram below. The bodies are an Assembly Council (the governing body of the CCDO), Climate Change Displacement Fund (CCDF), Climate Change Displacement Environment and Science Organisation (CCDESO), and Climate Change Displacement Implementation Groups.

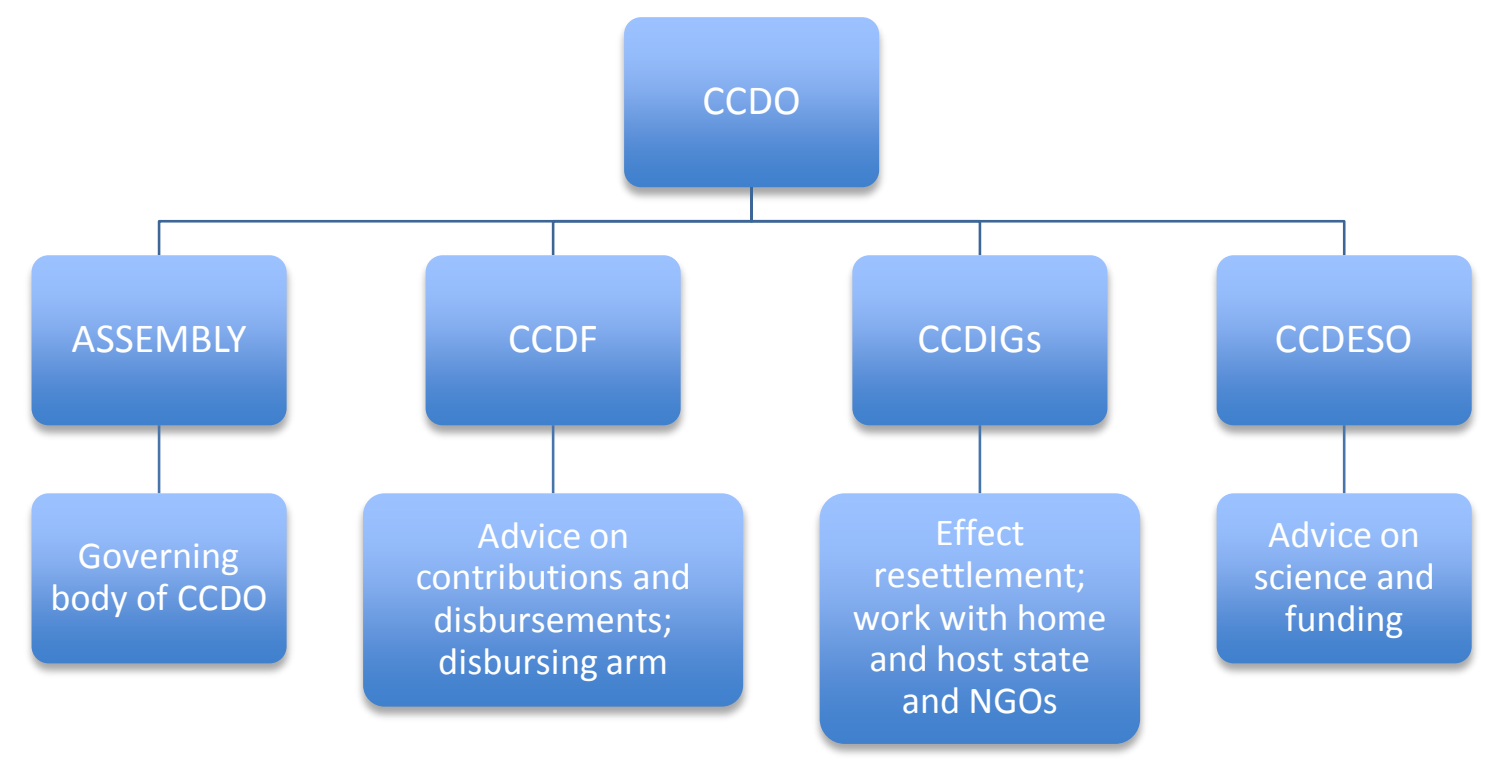

Broadly, the four proposed implementing bodies of the CCDO exist to provide advice and information to the CCDO Council for decisions, and implement the decisions when taken. The relationship and hierarchy between the proposed Assembly and 
CCDO Council is unclear. The Assembly would ratify financial contributions to the CCDF (following advice from the CCDF and CCDESO), and review the state of climate change science with a particular focus on implications for displacement. The proposed Assembly Council nominally sits below the CCDO Council, but as the former is comprised of state Party representatives it would probably overrule the CCDO Council in practice. In the UNFCCC, there are frequent restatements of the fact that the negotiations are a 'party driven process', meaning that state representatives hold the reins of progress and decision-making.

A CCDO Council is mentioned throughout the proposed Convention, but it is unclear exactly where this would sit in the hierarchy. Its functions are to assess requests for assistance and en masse designations of 'climate change displaced persons', and to set the direction and guide operations of the CCDO. The CCDF proposes the level of developed state contributions to the fund, and the level of assistance to developing state parties and CCDIGs. Following the CCDO Council decision on funding, the CCDF would work to disburse funds through state parties and the CCDIGs. Funding procedures are a crucial aspect of the proposed Convention, both politically and practically. The considerable implications of these proposed arrangements are discussed in more detail in the following section.

The CCDESO is designed to investigate issues of causality raised in the thesis sections above, in relation to whether the effects of climate change or human activity can be said to have wholly or partly caused a particular situation that requires people to migrate. The CCDESO will advise the CCDO on climate change science issues (particularly around slow onset and sudden events), and advise the CCDF on appropriate levels of funding assistance to developing state parties and CCDIGs. It would also monitor state parties' emissions levels to assist in determining their financial contributions to the Fund, which are based on measured emissions. The CCDESO would also conduct research and establish links with the IPCC, the UNFCCC's Subsidiary Body on Scientific and Technical Advice, and other organisations. 
The CCDIGs will effect resettlement, the CCDIG would be led by a representative of the CCDO. Depending whether migration is internal or external, membership would comprise some or all representatives of the following: home and host states, local and/or state governments, international organisations and relevant UN bodies (unspecified and somewhat mystifying in this context). The CCDIGs would also work with civil society at both ends of the migration process, and with Regional Committees.

The authors provide very little information on Regional Committees, other than references to their virtues. In practical terms, it seems they would be established to “...inform Council and CCDO decision-making of regional perspectives, views and developments; ... work closely with CCDIGs, and enable the unique situation of small island states to be addressed" (Ibid, p. 26). However, it is unclear whether the 'regions' would reflect geography or interest. For example, an Asia-Pacific 'region' grouping would probably reflect a very different set of perspectives and views than a Small Island States grouping. It is naïve to assume that all states' interests are equally represented in regional groupings, not least as some states in a region can neither afford to send a representative to meetings nor have the capacity to develop a specialist in a particular area.

In addition to these practical implementation bodies, there are mentions of an administrative arrangement tied through the entire structure, including a permanent secretariat. As this thesis is focused on the larger issues of the contribution the proposed Convention may or may not make to the approach to the potential problem of climate change-related migration, the specifics of the administrative arrangements will not be dealt with in detail. However, from the limited information the authors have provided about the arrangements, it is interesting that they have not addressed a consistent criticism of international and United Nations organisations, namely that the administrative support consumes a disproportionate amount of the organisation's entire budget and functionality. 
While the available descriptions of the proposed Convention have some interesting gaps, the authors have established a clear and interesting framework, which enables assessment of its potential contributions to the problem of responding to the potential for climate change-related migration.

\section{Assessment of the proposed Convention}

Hodgkinson, Burton, Anderson and Young's proposed Convention makes practical and theoretical progress towards addressing gaps in human rights protections and mechanisms for managing potential climate change-related migration. However, the authors are not convincing on the crucial aspect of the link between the theoretical justification for needing to develop a response to the potential problem, and that a Convention is the best way to respond. The design of the framework usefully examines how a response could work in practice, but some aspects of the design create political barriers to the proposed Convention's acceptance by states. A more strongly developed theoretical basis and justification could lead the authors towards a more acceptable practical design, or at least direct them to areas from which to create a framework. In general, further work is needed by both these authors and others, and by states and international organisations, to address the political issues of the nexus between recognition of the problem in relation and the requirement for a response.

Hodgkinson, Burton, Anderson and Young assume that there will be climate changerelated migrants, that the problem is near to hand, and that it will be significant. All of these assumptions are sound in themselves, as shown in Section A. However, it is a fairly obvious political reality that the international community of states must be convinced of the specific problem and that there is no current system which can manage it, before states are willing to part with funds - not to mention the land, resources, time, and potential political capital, among other things, associated with assistance to migrants. 
As discussed above we cannot find justification for a new system of management, funding, and human rights norms in simply identifying that there are likely to be people whose categorisation (in this case, 'climate change-related migrants') is not already sufficiently covered by international and domestic systems of support. Hodgkinson, Burton, Anderson and Young surprisingly did not mention a need for international coordination among governments within the frame of what currently exists, i.e. a United Nations-negotiated agreement, despite referring to this as part of the problem they were trying to solve.

This intervention logic question is, arguably, the most significant issue which the authors of the proposed Convention face. The stated justification is that, "there has been no coordinated response by governments to address human displacement, whether domestic or international, temporary or permanent, due to climate change". The authors go on to suggest that because climate change is global and people played a role in contributing to it, the international community must accept responsibility for managing the ensuing problem (Ibid, p. 3). At face value, this is all very sensible.

However as discussed in Sections A and B, it is spurious to overlook migration causes other than those effects which are directly attributable to climate change by using 'displacement' and suggesting that movement may be attributable to one factor only. The authors' stated justification simplifies the issue too far, and too thinly, essentially suggesting that because people move because of the actions of people, everyone must mitigate the effects of moving. But this gives us no clues as to precisely what is lacking at present and whether it is a problem we must address now, or why a Convention is the best solution to this.

The second part of the author's justification points closer to what seems to lie at the heart of their (unwritten) justification. This is because when a problem is fluid and widespread but cloaked under a range of long-standing challenges (such as extreme weather), our responses are typically disparate and uncoordinated. This, too, is undeniable, and at present as discussed in Section B there is in fact no coordinated 
response to the salient problem at the international level. But once again, the link between this lack of coordination and the need for a coordinated response is not made in the proposed Convention. Tellingly, the authors mention the need to address climate change-related migration depending on the local situation and the people's wishes, and this could be construed as an argument for an uncoordinated response, rather than a coordinated one.

Elsewhere in the paper is the assertion that "...ad hoc measures based on existing domestic regimes are likely to lead to inconsistency, confusion and conflict" (Hodgkinson, Burton, Anderson and Young, 2010, p.13). This bold statement is somewhat isolated, in that there is no supporting evidence or discussion surrounding it. Barnett, Burson and Bedford all make reference to the importance of bilateral discussions and arrangements between neighbouring countries or those with an existing relationship in addressing climate change migration. Furthermore, despite this and another comment in the Convention to the effect that uncoordinated climate change migration will cause conflict, this link has largely been discredited in the last couple of years. As with migration, ascertaining that climate change is the cause of conflict is tenuous, particularly as much of the evidence now points to economic factors and poor governance being the more significant drivers of conflict. Interestingly, these are also the factors that cause the effects of climate change to be more significant in countries most likely to be the origin of climate change migrants (Barnett, 2001; Carius and Maas, n.d.).

However, they acknowledge and draw out the important consideration that even while the current situations of climate change-related migration (if specific cases could be readily identified) are currently local and largely do not trouble the international community en masse, the scope of the problem and the requirement for a wider response grows as the effects of climate change have a greater negative impact on peoples' lives. The authors' contribution is in the forward-looking assumptions they make about the state of the problem in the future, and the acknowledgement that political developments with practical outcomes such as their proposal move slowly and need to be developed over a long period of time. This 
proposed Convention is not designed for use tomorrow, but to deal with a problem as it exist in the future, on a more difficult scale and scope than its current state.

Acknowledging a gap in the existing international human rights protection frameworks enabled Hodgkinson, Burton, Anderson and Young to create a mechanism for practically managing large-scale movement of people between countries and within countries, under the oversight of the international community of states. Most importantly perhaps, the practical detail it is accorded in the proposed Convention provides a framework for funding the movement of people. This puts climate change-related migration in an exalted position in relation to other types of migration.

Hodgkinson, Burton, Anderson and Young's stated aim is to provide a “...comprehensive, global solution" (Ibid, p.12) and their research into the issue and on other proposals identified aspects that must therefore be included in a Convention. They reached the following conclusions, on which the proposed Convention is based. First, the Convention must include both types of migration likely to result from the effects of climate change - internal and cross-border. Second, an adequate and specific definition must be established to appropriately frame the subjects of the Convention. Third, ensuring the appropriateness of the instrument and its effectiveness for those who would use it requires taking into account the wide range of circumstances from which climate change migrants could emerge. For example, the needs of people from small island states will be very different from those of people from a delta region in a large state.

(Hodgkinson, Burton, Anderson and Young have made specific provisions for inhabitants of small island states in their Convention. This renders the Convention of particular interest for New Zealand and its Pacific neighbours.) Fourth, this Convention also establishes principles for application to bilateral agreements between small island states and host states. Finally, the Convention works through a level of detail (establishing a governance structure) that is not present in other 
Conventions and a useful point of reference when considering the likely practical use of the Convention, and its likely acceptance by states.

\section{Weak points of proposal}

As discussed above, while the Refugee Convention could in theory be modified to accommodate climate change, Burson recommends proceeding with caution before opening up "...the most successful international protection instrument currently existing in international law" (Burson, 2010, p. 161). However, that very success means that using the Refugee Convention as a source of facets and principles for this Convention is a wise move for Hodgkinson, Burton, Anderson and Young. Burson also notes that because gaps exist does not mean that climate change migrants are devoid of any rights protection at all. They are covered under existing multilateral treaties, such as the 1966 ICCPR and 1966 International Covenant on Economic, Social and Cultural Rights (Burson, 2010, p. 169).

\section{Responsibility and funding}

Hodgkinson, Burton, Anderson and Young's framework equates responsibility with response, in that the authors have identified a responsible 'owner' of the problem of climate change-related migration, and created a system which draws from those responsible to create a tangible response in the form of financial assistance to migrants and hosts. We presume that financial assistance also flows from developed countries to the system itself, the secretariat and functions of the system, as well as provide assistance to migrants - but it seems safe to draw this conclusion on the basis of other international and UN organisations. The underlying assertion suggests that climate change is considered anthropogenic, and developed states considered those that caused and continue to cause it, and therefore developed states should bear the costs of dealing with the direct and indirect effects of climate change including migration. 
The primary issue with linking the response to responsibility in this case is, as discussed in Section A, that it is not a direct and linear link between anthropogenic climate change and migration. Furthermore, identifying developed states as the responsible parties is not untrue or unfair, but the picture is more complex than the authors' simple phrasing and system suggests, and will only get more rather than less complex as the patterns of emission and mitigation develop in the future.

The proposed Convention directly links funding ratios to reported emissions. The CCDESO's monitoring of emissions is a duplication of the UNFCCC's established role in monitoring emissions. It would seem more transparent and a better use of (presumably limited) resources to use existing reputable UNFCCC information, with its good historical record in this complex area, rather than creating another duplicate set in this context. The UNFCCC systems have also dealt with the complexities of how a state measures its emissions, particularly historical emissions.

The system of financial contributions under the proposed Convention would be based on the level of emissions, and the authors suggest that the developed/developing split across states will play out neatly in the financial system, with developed states putting money in and developing states taking money out. However, the authors have not mentioned what metric they are using to determine which are developed and which are developing states.

This is important, as mentioned above, because for example China and Brazil - both are probably considered 'developing' states by the authors - yet are emitting well above many developed countries in the amount of their emissions. The respective emissions profiles of the 'BRIC' countries (Brazil, Russia, India, China) are projected to rise over the coming decades, while countries such as the US and many of those in Western Europe have a slower rise, or in some cases a fall in projected emissions. States also have a tendency to see it as their sovereign right to decide how much money they wish to allocate to a particular mechanism, rather than having it decided for them. 
If the authors wish the proposed Convention to be adopted by the international community and a response developed, the political aspects of their proposal, such as this, will need a far greater degree of scrutiny and management to be acceptable. As it is, developed countries would be unwilling to spend yet more money in a time of international financial crisis and hardship to fund an arrangement that duplicates functions and does not have what would be seen as a 'fair' system for deciding appropriate contributions.

In looking at the specifics of what would be funded, Hodgkinson, Burton, Anderson and Young's proposed Convention is intended to primarily address "...slow-onset, gradual displacement, which is more likely to be able to be established as induced by anthropogenic climate change than a sudden disaster" (Hodgkinson, Burton, Anderson and Young, 2010). In line with academic consensus on the subject, displacement is viewed as a form of adaptation, and the Convention includes consideration of provision for pre-emptive resettlement. It also explicitly covers both internal and cross-border migration, noting that the former is most likely given cost and socio-economic factors involved in decision-making on migration.

The Convention recognises and respects the existing distinction between these two forms of migration, and acknowledges the primacy of the state and nonintervention. It does this by ensuring that "...assistance and protection obligations generally go no further than existing instruments; the Convention would operate within the present international law distinction between internal and international displacement, and those moving across state borders would be entitled to rights based on the Refugee Convention" (Ibid, p. 17). The Convention also recognises that “...national authorities have the primary duty and responsibility to provide protection and humanitarian assistance to CCDPs within their jurisdiction" (Ibid). 
Hodgkinson et al. give a two-fold intervention rationale for their Convention: historical responsibility and gaps in rights protection regimes. Historical responsibility does not really lead to the need for a Convention in particular. Historical responsibility argues that emitters are responsible for securing the future of those countries worst affected by climate change, but it does not necessarily follow that an international instrument such as this Convention is the only way to secure that future. Arguing that the primary focus of the international community should be the prevention of de jure and de facto statelessness, Burson suggests that possible policy settings are formal ceding of sovereignty to a host state so that government exists in a different territory, adjustments in nationality laws of the host state to allow dual citizenship during transit periods, or adjustments to existing policy around naturalisation requirements (Burson, 2010, pp. 168-9). These would all assist to secure peoples' future, but none require an international Convention.

Two aspects underlying the proposed Convention's funding system raise further theoretical issues that are occupying other fora, and yet to be resolved. The section proposes that developed state parties make mandatory contributions to the Climate Change Displacement Fund, "...on the basis that states and state parties to the Convention have common but differentiated responsibilities;" (Hodgkinson, Burton, Anderson and Young, 2010, p.29). The mandatory nature of the contribution is somewhat contradictory to the assertions and proposal features elsewhere in the document that retain state primacy. Furthermore, the principle of 'common but differentiated responsibilities' is contentious in this formulation.

Taken from the UNFCCC (although Hodgkinson, Burton, Anderson and Young do not reference that document), the full phrase is, importantly, 'common but differentiated responsibilities and respective capabilities" (emphasis added). The second part of the principle puts in a brief (but unacknowledged or explained) appearance on the following page, but is otherwise absent. The principle acknowledges that all countries have a responsibility to tackle climate change, but that states' responsibility for the current state of the environment is different some emitted more greenhouse gases and therefore bear a larger burden of 
responsibility. The second part of the principle, 'respective capabilities' is crucial as it refers to states' ability, both economic and human, to address the effects of climate change both domestically and internationally.

Omitting the second part of the principle has consequences for the functions of the Convention. Hodgkinson et al. noted that the principle has "...a number of implications, including the imposition of environmental obligations which differ between states" (Hodgkinson, Burton, Anderson and Young, 2010, p. 30). One of these, alluded to but not noted by the authors, is that the second part of the principle could be used to encourage developing countries with sufficient resources to contribute to the CCDF, thereby increasing the pool of available funding to support those with little responsibility and little resource. The authors note that the use of this principle to apportion funding requirements is used by a number of other proposals to address climate change migration, including those proposals which Hodgkinson et al. drew on to construct their own - Biermann and Boas (2007), and Docherty and Giannini (2009). While this principle is popular in academic proposals, it could encounter resistance from potential state parties unwilling to commit to modalities of a funding mechanism before negotiation.

The proposal elaborates the modalities of the funding mechanism, suggesting that to determine how much each state party must pay: “...the CCDESO would advise the Fund with regard to those contributions, with reference to emissions levels (whether historical or current, per capita etc)" (Ibid, p. 29). While it is useful to have a level of detail that is absent from other proposals, the measure (and process) for assessing appropriate contributions is one of the issues that states will want to negotiate in detail, given the potentially significant consequences for their fiscal health. There would also be much negotiation around who sits on the CCDESO and Fund boards, given their significant decision-making power on contributions and other financial matters. Also of interest to many states may be the administrative cost associated with setting up the institutions of the Convention, particularly in relation to the amount of money they need to contribute. 
Political and practical feasibility

While it is useful to have such detail laid out in the Convention proposal, states are unlikely to show interest in it for taking up to the negotiation stage unless all issues are up for negotiation, including the funding modalities and organisational structure. The authors could also consider whether there would be an expectation that the money is 'new', or whether a state could direct part of its annual aid budget to the Convention's mechanism. To be realistically attractive to states, funding needs to be politically palatable with domestic constituencies, and at the time of writing many states will find themselves faced with a population less interested in funding issues that are not necessarily immediate and vital, when confronted with natural disasters and economic crises.

Another aspect of the justification for the proposed Convention, gaps in rights protection regimes, is somewhat stronger than that of responsibility equating to response, but again does not necessarily point to a Convention as the necessary form for a response. The proposed Convention points to areas where there could potentially be gaps in human rights protections for climate change-related migrants, but the reader is left with an impression that the suggestion that there may be gaps is justification enough for creating another regime to protect people. It seems that the negative effects of climate change themselves constitute an assault on a person's human rights, and other contributing factors (such as human activity or neglect) are swept aside.

Hodgkinson, Burton, Anderson and Young have defined climate change displaced persons as "...groups of people whose habitual homes have become - or will, on the balance of probabilities, become - temporarily or permanently uninhabitable as a consequence of a climate change event". While long, the definition covers a few of the more problematic aspects of defining people who move in relation to the effects of climate change. It considers the fragility of prediction and timing, and the use of 'uninhabitable' and 'homes' is broad enough that a range of context-specific circumstances could be captured. Presumably the modalities around a person's 
circumstances meeting the criteria based on the definition would be worked out through the process of negotiation and setting the parameters of the implementing bodies. The use of 'on the balance of probabilities' also gives the space required to include pre-emptive migration - it is entirely possible that a person's home may be expected to be uninhabitable but the day never actually arrives, and in the meantime they have made a decision to move on the basis that they do not wish to await the final destruction. It also ensures that those who have the foresight and means to migrate before the worst struck would still, theoretically, be covered by the Convention.

The authors also define a 'climate change event' as “...sudden or gradual environmental disruption that is consistent with climate change and to which humans very likely contributed" (Ibid, p.10). This captures both extreme events and slow-onset events like sea level rise and changes to rainfall patterns.

\section{Spectrum of actions and migration types}

Noting the now wide acceptance that climate change-related migration exists along a continuum between forced at one end to voluntary at the other, Burson suggests that the considerable grey area in between is potentially problematic in terms of issues of extremity. How dry must a village be for its inhabitants to count as 'forced' migrants, or how far underwater? Must the water or the drought be solely an effect of climate change?

For the Pacific context in particular, an ideal definition would acknowledge and clarify the relationship between the effects of these two types of human activity (direct and indirect). As Bedford explains, the population-environment problems confronting residents in parts of Kiribati and Tuvalu are not new, but are compounded by increasing concentrations of population in particular urban areas, and intensifying pollution of the main sources of freshwater which sustains the islands' life (Bedford, 2008, p. 124). Both direct and indirect human activity have 
effects on the islands' environments, so need to be addressed, and it is likely that the response would include similar if not the same actions.

Adaptive responses to declining water quality and quantity are unlikely to differ on the basis of cause, and responses should avoid directing funding streams on the basis of cause. That said, issues of responsibility for environmental degradation become more important when there are large sums of money or the movement of many people involved. Causality aside, now that the effects of both direct and indirect human activity have merged to create a serious problem for the islands there is understandably an inclination to follow the money to the potentially fastest and most significant funding source. Hodgkinson, Burton, Anderson and Young do not really address this issue, although it could have a significant impact on the success of the Convention.

\section{Principles}

Hodgkinson, Burton, Anderson and Young envisage a governance structure for the Convention with "...a role for regional committees and multi-disciplinary collaborations across developed and developing states, and including government and non-government organisations" (Hodgkinson, Burton, Anderson and Young, 2010, p. 24). The structure bears some similarity to that of the UNFCCC, but would in all likelihood be changed by states during the negotiation process. While the structure may seem straightforward, the functions of some arms duplicate those already in existence, and given that new organisations require a significant amount of money to establish and resource, states may prefer to utilise existing organisations by adding specialist units within the existing structure.

For example, the Climate Change Displacement Environment and Science Organisation duplicates some functions of the UNFCCC, such as monitoring of state emissions. Its unique functions relate to the decisions around both incoming and outgoing funding, and "climate change and displacement research" is already undertaken by the IPCC, IOM, and many other organisations. Adding another seems 
superfluous, and in addition requirements for reporting could place an unnecessarily onerous burden on states with few resources to manage scientific reporting. There is no reference in the Convention to financial assistance to states (developed or developing) for compiling emissions information, and if the CCDESO is to establish links with the IPCC and UNFCCC's Subsidiary Body for Scientific and Technological Advice, presumably it could share information with those bodies.

The functions of the Climate Change Displacement Fund include working with recipients and Implementation Groups on the deployment of funds to support people during their moves. This is a relatively operational-level exercise, and it seems that the CCDF would need to be staffed by a wide range of people with a range of expertise - from financial management specialists who can transfer emissions levels to funding contributions, to those who have operational knowledge of migration and adaptation actions to work on fund deployment. That the authors evidently want to ensure that funding gets to where it is needed (this is presumably the intention of such a range of functions, the rationale not actually being elaborated in the text). However, such activity is undeniably costly, especially in combination with appropriate staffing of other institutions and the Convention's secretariat.

While the authors have drawn on existing mechanisms such as the UNFCCC to design the Convention's structure, they have also based the principles laid over the structure on existing mechanisms. This adoption would stand the Convention in good stead for consideration by states, as they would already be largely comfortable with the principles therein. One aspect that does not get included is soft law. While the Convention refers to the Refugee Convention and UNFCCC, there is no reference to soft law. Burson suggests that institutions should draw on soft law instruments, such as the 1998 Guiding Principles on Internal Displacement, 2005 Pinheiro Principles on housing and shelter, and the Hyogo Framework of Action on Disaster Preparedness. For the Pacific, this is an important point as the region has developed a number of strategies for responding to the negative effects of climate change. 
Bedford suggests that New Zealand and Australia should make creative use of existing immigration policies to manage climate change-related migration from the Pacific, and refers specifically to the New Zealand Pacific Access Category (Bedford, 2008 , p. 94). He also recommends regional collaboration in strategy development and progressive reductions in population size in particularly vulnerable Pacific countries to gradually manage migration. In relation to Kiribati and Tuvalu, Bedford raises the "...possibility of New Zealand moving towards a pro-active policy with regard to relocation of I-Kiribati and Tuvaluans and anticipation of a need for more resettlement options for atoll dwellers in the future" (Ibid, pp. 94-5).

The Convention views climate change-related migration as an adaptive response to climate change and specifically includes provisions for pre-emptive movement of people before their homes become uninhabitable. However, Hodgkinson, Burton, Anderson and Young propose en masse designations of the status of 'climate change displaced persons', through a process of request and determination by states and Convention institutions (Hodgkinson, Burton, Anderson and Young, 2010, p.9). However, it is not clear whether the en masse designation would apply to a community, village, individual and identified others, or to the entire state population.

Bedford advocates for gradual movement of people rather than en masse, as adjustments to New Zealand's policy settings "...would not obviate the need for continued investment in improving living conditions and economic opportunities in the [Pacific] islands...[voluntary migration would] complement existing aid programmes" (Bedford, 2008, p. 96). Immigration policies would be developed for long-term problem resolution, and aid policies for short- to medium-term improvement in living conditions.

The inclusion of pre-emptive movement in Hodgkinson, Burton, Anderson and Young's proposed Convention does indicate a good understanding of the issues facing small island states, where staying to the last is not necessarily an option. However, the Convention makes no reference to Burson's suggestion of dovetailing 
migration policies with aid support to ensure suitable conditions for those who remain on the islands. This is a crucial point as research has found that some older Pacific Islanders would prefer to stay in their homes, or at least on their atolls and in their countries, rather than migrating - regardless of the consequences (Bedford, 2008; Gemenne and Shen, 2008).

Small island states are allocated a section of the Convention, in relation to the slowonset nature of their plight and high vulnerability to the effects of climate change (Hodgkinson, Burton, Anderson and Young, 2010, pp. 41-45). This section sets out principles that the authors think should be applicable to bilateral climate changerelated migration agreements, and suggests that such agreements should be negotiated under the aegis of the CCDO and regional committees. The principles are proximity, self-determination, and preservation of intangible culture.

The principle of proximity would guide agreements between states with the aim of the least separation of people from their home, referred to in the Convention as their "cultural area". The self-determination principle draws on the UNICESCR to ensure that people decide when they leave their homes, and where they choose to go. It also underpins that people should be able to stay on their island as long as practicable - as Bedford suggested. Adaptation funding would also be provided through the Convention's fund to assist with this aim - although this function will also be carried out by the UNFCCC Green Fund, and is also managed through bilateral aid programmes. Ensuring that these functions complement one another and do not duplicate would be important, and relatively difficult. It seems that a preferable approach would be for the UNFCCC Green Fund to provide adaptation support in conjunction with bilateral aid programmes, and the Convention's fund restrict its activities to providing funding to support the migration process itself.

The third principle, preservation of intangible culture, draws on the en masse designation system to enable communities or other groups to "formulate solutions that would keep the integrity of a group intact, which could help preserve cultures and national identities" (Ibid, p. 44). Here again the essential principle has been 
adopted from the Refugee Convention, and it should be remembered that (as Burson pointed out) migrants are not devoid of rights in relation to the preservation of their cultural identity. Hodgkinson, Burton, Anderson and Young draw on the 'Convention for the Safeguarding of the Intangible Cultural Heritage' as well, for further protection of the culture of small island state inhabitants. These three principles are useful for application to bilateral agreements, but it seems that it is only if bilateral agreements are negotiated under the Convention that they can be brought to bear on the negotiation outcome, unless states decide to unilaterally draw the principles to the process operating outside the Convention.

SIS in the Pacific have indicated that they are in need of assistance immediately, not at some point in the future, and the assistance is needed to deal with internal and cross-border migration, and to address the wider range of climate change effects to which their countries and communities must adapt. It seems that the principles laid out here do not specifically relate to small island states, as adaptation funding and protection of cultural rights should be extended to all climate change-related migrant communities.

Proximity is the only principle that bears more relevance for the Pacific, but the suggestion in the Convention is that this would translate into a movement to Australia or the United States. The logical conclusion one would draw from the principle is that it would translate into south-south cooperation, as Pacific people may want to move to other Pacific countries. Indeed, research conducted on drivers of migration ascertained that people may want to move to a similar lifestyle and society, in which case they indicated a move to another Pacific community or elsewhere in their own country; or a relatively similar lifestyle and community where others from their country or community already lives in which case they indicated a move to New Zealand or Australia. As all the authors are Australian and the Convention documents make reference to Kiribati and Tuvalu, this seems an unusual oversight, unless intra-Pacific movement is considered to be 'internal'. Regrettably, the Convention is silent on this point. 
In drafting the proposed Convention Hodgkinson, Burton, Anderson and Young have drawn on existing legal instruments and international mechanisms to create a Convention that could form a very useful basis for negotiation by states. Despite some issues with concepts being underdeveloped (and functionality being somewhat overdeveloped for political purposes), the basic premise of the Convention is strong. That said, states such as New Zealand are likely to have qualms about the funding modalities and the creation of new institutions where existing ones already carry out the same functions. The design and membership of the bodies would also be a point that would need further elaboration and negotiation among states and other relevant actors.

The principles established in the Convention are useful and there could be value in New Zealand and other countries involving them in policymaking as guides for agreements between states on climate change-related migration. One principle is glaringly absent from the Convention, as there is no requirement for hosts to accept migrants (Ibid, p. 15). In theory this is not problematic, but Hodgkinson et al do not clarify where the imperative to accept migrants would come from, unless we are to assume that it is a sense of guilt stemming from historical responsibility. However as Burson points out, there is a fundamental problem with rights protection of climate change-related migrants if they have no guaranteed right to reside in the host country, regardless of theoretical principles around a state's responsibility for part of the cause of their move.

Elevating the plight of small island states as those most likely to be deeply affected soon is a welcome development for a group of states that have limited political and fiscal capacity for drawing the attention of the international community to their plight, or for dealing with the problem themselves. However, the proposed Convention does not mention taking account of the difficulties faced by some small island states, which do not have the human or technical capacity to deal with managing such a problem at the ground level or the accountability requirements attached to funding. These such requirements are inevitable, as donors are ultimately responsible to their taxpayers. In some cases small island states in the 
Pacific request assistance from donors and/or regional organisations for managing funding disbursement and accountability, and such relationships do not seem to have been considered by the authors of the proposed Convention. While this may seem to be one of the smaller aspects of the proposal, given that the authors are all based in Australia it is surprising that they have not more closely examined the practical situation of small island states in their region.

In sum, the proposed Convention draws up some issues that need consideration by all states, around the potential for climate change-related migration and the associated costs. However, Hodgkinson, Burton, Anderson and Young's proposed Convention is not currently framed in a way that would be acceptable to those who will be asked to fund it, probably not to those who would probably be on the receiving end. Practically, it takes steps towards a management structure that involves checks and balances on the scientific and fiscal aspects of climate changerelated migration, but would do well to look at utilising existing systems and information rather than duplicating an unattractive trait to potential donors. 


\section{Conclusion}

It is likely that the effects of climate change will have an impact on the lives and livelihoods of some people, that in conjunction with other factors influencing their decisions, they decide that it is necessary to migrate to enjoy a satisfactory life. This migration could be internal, within their state boundaries, or external, to another country. Regardless of the direction and reasons for movement, it is clear that existing approaches to the problem of climate change-related migration are insufficient for managing it to an extent that ensures peoples rights are protected.

The international community has a vested interest in ensuring sound intervention logic an approach with such broad application such as this. As yet, the international community has not developed a coordinated approach to the potential problem of climate change-related migration and related issues, despite the proliferation of discussions and frameworks that is being thought up. There are various factors preventing or at least delaying this coordination, not least that it remains unclear whether there is a convincing argument for needing a specific framework to manage this type of migration.

Existing patterns of migration and decision-making, and the spectrum of actions from adaptation to migration are key factors that have been to a certain extent swept aside by the authors' clearer, simpler picture of climate change-related migration. However, these factors are vitally important during the process of considering an international approach so as to not exacerbate the very problem that is being addressed. If existing migration and adaptation strategies are not considered as part of the approach to addressing potential climate change-related migration, more people could be forced from their homes because of the unchecked effects of climate change and the inability to adapt to the changing world. 
It is obvious that the potential problem of climate change-related migration is significant, but it is not clear that creating this proposed approach to it would not disadvantage other types of migrants in the process. Consideration of an approach (including its necessity) is in part constrained by the complexity of the issues at hand. Migration is not new, unique, or particularly special in the context of the human condition, nor is climate change-related migration identifiably unique from other types of migration so as to justify its separate treatment and potential resulting inequities.

This last consideration may seem callous but is in fact crucial if those attempting to smooth the path of climate change-related migrants do not wish to disadvantage economic migrants or refugees. Similarly, it is crucial if we do not wish to subjugate existing development challenges to this issue that has gained significant prominence in recent years in ways that nonetheless necessarily furthered its cause.

Despite the significant research, attention, and policies that have been developed on the potential for climate change-related migration, there is nothing drawing the approaches together and they do not appear to be necessarily aware of or utilising each other's developments. This suggests that there is a need to find a way to fill the gaps between existing work based on non-climate change-related migration situations, and the work underway at different levels. However, all of these assumptions, as well as the approaches already developed, have assumed that there needs to be an approach to dealing with climate change-related migration, that existing mechanisms are inadequate.

The proposed Convention created by Hodgkinson, Anderson, Burton and Young creates a practical framework for the management of potential climate changerelated migrants and establishes mechanisms for providing financial support and migration assistance through a centralized body. It has made practical and theoretical contributions to the work on addressing gaps in human rights protection 
mechanisms and functional management of this potential type of movement of people, which is not catered for under many existing mechanisms.

However, the contribution of the proposed Convention is not so significant as to solve the potential problem, not least as it appears to be unaware of some existing approaches that have made significant contributions in their areas. For the international community as a whole, further work is needed to address the political issue of the nexus between identifying a need and justification of a response, and on the practical issues surrounding the potential problem of climate change-related migration. 


\section{Reference List}

Ambo Declaration. (2010). Tarawa Climate Change Conference. Retrieved from http://www.climate.gov.ki .

Asian Development Bank. (2011). Climate Change and Migration in Asia and the Pacific. Asian Development Bank: Philippines

Associated Press. (2010, 25 March). Island Disappears after 30 Year Dispute. Retrieved from http://www.stuff.co.nz .

Barnett, J. (2001). Adapting to Climate Change in Pacific Island Countries: The Problem of Uncertainty. World Development, Volume 29, 977 - 973.

Barnett, J. (2003). Security and Climate Change. Global Environmental Change, Volume 13, 7- 17.

Barnett, J., and Adger, N. W. (2003). Climate Dangers and Atoll Countries. Climactic Change, Volume 61, $321-337$.

Barnett, J. (2005). Titanic States? Impacts and Responses to Climate Change in the Pacific Islands. Journal of International Affairs, Volume 59, $203-219$.

Barnett, J., and Webber, M. (2010). Accommodating Migration to promote Adaptation to Climate Change. World Bank Policy Research Working Paper Series. Retrieved from http://ssrn.com/abstract=1589284.

Bedford, R.D. (2008). Pasifika Mobility: Pathways, Circuits and Challenges in the $21^{\text {st }}$ Century. In A. Bisley (Ed.), Pacific Interactions: Pasifika in New Zealand, New Zealand in Pasifika (pp. 135 -184). Wellington: Victoria University of Wellington.

Betaille, J. (2008). Draft Convention on the International Status of EnvironmentallyDisplaced Persons. Revue Europeenne de Droit de L'Environnement, Volume 4, 395.

Biermann, F., and Boas, I. (2007). Preparing for a warmer world: Towards a Global Governance System to Protect Climate Refugees. Global Governance Working Paper, Volume 33, $21-32$.

Black, R. (2001). Environmental refugees: myth or reality? Retrieved from http://www.unhcr.org . 
Black, R., Kniveton, D., Skeldon, R., Coppard, D., Murata, A., and Schmidt-Verkerk, K. (2008). Demographics and Climate Change: Future Trends And their Policy Implications for Migration. United Kingdom: Development Research Centre on Migration, Globalisation and Poverty.

Brown, O. (2008). Migration Research Series No. 31: Migration and Climate Change. Geneva: International Organization for Migration.

Burson, B. (Ed.). (2010). Climate Change and Migration: South Pacific Perspectives. Wellington: Victoria University of Wellington Institute of Policy Studies.

Canziani, O.F., Parry, M.L., Palutikof, J.P., van der Linden, P.J., and Hanson, C.E. (Eds.). (2007). Climate Change 2007: Impacts, Adaptation and Vulnerability: Contribution of Working Group IV to the Fourth Assessment Report of the Intergovernmental Panel on Climate Change: Summary for Policymakers. Cambridge, United Kingdom: Cambridge University Press.

Campbell, J. (2010). Climate Change and Population Movement in Pacific Island Countries. In B. Burson (Ed). Climate Change and Migration: South Pacific Perspectives (pp. 29-50). Wellington: Victoria University of Wellington Institute of Policy Studies.

Carius, A., and Maas, A. (n.d.). Territorial Integrity and Sovereignty: Climate Change and Security in the Pacific and Beyond. Retrieved from http://climsec.prio.no/papers/.

Coates, B. (2010). Responses to Questions. Discussion during Climate Change and the Pacific: What should we be doing about it? Conference. Wellington, New Zealand.

David, L., Bender, L., Burns, S.Z., and Skoll, J. (Producers), \& Guggenheim, D. (Director). (2006). An Inconvenient Truth [Film]. Thailand: Participant Media.

Docherty, B., and Giannini, T. (2009). Confronting A Rising Tide: A Proposal for a Convention on Climate Change Refugees. Harvard Environmental Law Review, Volume 33, $349-355$.

Dun, O., and Gemenne, F. (2008). Defining Environmental Migration. Forced Migration Review, Volume 31 (11), 10-11.

Dunstand, S., and Canham-Harvey, G. (2009). Climate Change in the South Pacific: Issues and Possible Responses. As presented at Institute of Policy Studies Conference on Climate Change and Migration. Wellington, New Zealand.

Eastwood, P. (2009). NZAID Support to Climate Change Adaptation in the Pacific. As presented at Institute of Policy Studies Conference on Climate 
Change and Migration. Wellington, New Zealand.

Gemenne, F., and Shen, S. (2009). United Nations University Environmental Change and Forced Migration Scenarios: Tuvalu and New Zealand Case Study Report. Retrieved from http://www.each-for.eu .

Hodgkinson, D., Burton, T., Anderson, H., and Young, L. (2010). The Hour When the Ship Comes In: A Convention for Persons Displaced by Climate Change. Retrieved from http://www.ccdpconvention.com .

International Organisation for Migration. (2004). International Migration Law: Glossary on Migration. Geneva: International Council on Human Rights.

International Organisation for Migration. (2008). World Migration Report 2008: Managing Labour Mobility in the Evolving Global Economy. Geneva: International Organisation for Migration.

International Organisation for Migration. (2009). Migration, Climate Change and the Environment. Geneva: International Organisation for Migration.

Macey, A. (9 July 2009). Global or regional management of immigration in the context of climate change. Paper presented at Conference 'Climate change and migration in the Pacific: policy perspectives'. Wellington: New Zealand.

Mimura, N., Nurse, L., McLean, R.F., Agard, J., Briguglio, L., Lefale, P., Payet, R., and Sem, G. (2007). Small Islands. In M.L. Parry, O.F. Canziani, J.P. Palutikof, P.J. van der Linden and C.E. Hanson (Eds.). Climate Change 2007: Impacts, Adaptation and Vulnerability: Contribution of Working Group II to the Fourth Assessment Report of the Intergovernmental Panel on Climate Change ( $\mathrm{pp}$ 687-716). Cambridge: Cambridge University Press.

Mortreux, C., Barnett, J. (2009). Climate change, migration and adaptation in Funafuti, Tuvalu. Global Environmental Change, Volume 19, $105-112$.

Morgan, G., and McCrystal, J. (2009). Poles Apart. Auckland: Random House.

Myers, N. (2001). Environmental refugees: a growing phenomenon of the $21^{\text {st }}$ century. The Royal Society, Volume 357, 609-613.

Nicholls, R. (2003). Case study on sea-level rise impacts. Paris: Organisation for Economic Co-operation and Development.

Niue Declaration. (2008). Signed by Leaders at the $39^{\text {th }}$ Pacific Islands Forum meeting. Retrieved from http://forum.forumsec.org .

New Zealand. (2007). Statement to the United Nations Security Council. Delivered by 
H.E. Rosemary Banks, 17 April. Retrieved from

http://www.mfat.govt.nz/Media-and-publications/Media/MFAT-

speeches/2007/0-17-April-2007.php.

New Zealand Ministry for the Environment. (2010). Climate Change Information New Zealand. Retrieved from http://www.climatechange.govt.nz .

OCHA. (2008). Pacific Islands: Abnormally High Sea Levels, Situation Report 1. Geneva: Office of the United Nations High Commissioner for Human Rights.

OHCHR. (2009). Report of the Office of the United Nations High Commissioner for Human Rights on the Relationship Between Climate Change and Human Rights, A/HRC/10/61. Geneva: OHCHR.

Pacific Islands Forum Communique. (2010). Signed at the $41^{\text {st }}$ Pacific Islands Forum, Vanuatu. Retrieved from http://forum.forumsec.org .

Plume, H. (2009). Climate Change and Migration in the Context of the Nairobi Work Programme on Adaptation. As presented at Institute of Policy Studies Conference on Climate Change and Migration. Wellington, New Zealand.

Reisinger, A. (2009). Climate Change 101. Wellington: Victoria University of Wellington Institute of Policy Studies.

Reuveny, F. (2007). Climate Change-Induced Migration and Violent Conflict. Political Geography, Volume 26, 656-673.

SPREP. (2005). Climate Change, Variability and Sea Level Change. Retrieved from http://www.sprep.org/topic/climate.htm.

Stern, N. (2006). Stern Review on the Economics of Climate Change. Retrieved from http://webarchive.nationalarchives.gov.uk/+/http:/www.hm-

treasury.gov.uk/sternreview index.htm

Storey, D., and Hunter, S. (2010). Kiribati: An Environmental 'Perfect Storm'. Australian Geographer, Volume 41, (2), 167- 181.

Tevi, F. (2010). Discussions during Conference on Climate Change and the Pacific: what should we be doing about it? Wellington, New Zealand.

Tong, A. (2009, 23 June). Statement to the Forum Human Impact of Climate Change. Delivered by H.E. Anote Tong Beretitenti (President) of the Republic of Kiribati. Geneva, Switzerland.

United Nations Framework Convention on Climate Change. (2010). Outcome of the Work of the Ad Hoc Working Group on Long-Term Cooperative Action under the Convention, COP16. Cancun: Mexico. 
(a) United Nations Framework Convention on Climate Change. (2010). Adaptation. Retrieved from http://unfccc.int/adaptation/items/4159.php.

United Nations High Commission for Refugees. (1998). Further Promotion and Encouragement of Human Rights and Fundamental Freedoms, Including the Question of the Programme and Methods of Work of the Commission on Human Rights, Mass Exodus and Displaced Persons. In United Nations Commission on Human Rights e/CN.4/1998/53/Add.2, $54^{\text {th }}$ Session. Geneva: Switzerland.

Williams, A. (2008). Turning the Tide: Recognising Climate Change Refugees in International Law. Law and Policy, Volume 30, 502 - 505.

World Bank. (2000). Cities, Seas, and Storms: Managing Change in Pacific Island Economies: Volume IV - Adapting to Climate Change. Washington DC: World Bank.

World Bank. (2010). Reducing the Risk of Disasters and Climate Variability in the Pacific Islands: Republic of Kiribati Country Assessment. Washington DC: World Bank. 